Review

\title{
Silicon prepared by electro-reduction in molten salts as new
}

\section{energy materials}

Tingting Jiang ${ }^{\mathrm{a}^{*}}$, Xinyi $\mathrm{Xu}^{\mathrm{a}}$, George Z. Chen ${ }^{\mathrm{a}, \mathrm{b}, \mathrm{c}^{*}}$

${ }^{a}$ The State Key Laboratory of Refractories and Metallurgy, College of Materials and Metallurgy, Wuhan University of Science and Technology, Wuhan 430081, Hubei, China

b Electrochemical Technologies Group, Faculty of Engineering, University of Nottingham, Nottingham NG2 7RD, UK

${ }^{\mathrm{c}}$ Electrochemical Technologies Group, Faculty of Science and Engineering, University of Nottingham Ningbo China, Ningbo 315100, Zhejiang, China

*Corresponding authors. E-mail addresses: ttjiang@wust.edu.cn (T. T. Jiang), George.chen@nottingham.ac.uk (G. Z. Chen).

\section{ABSTRACT}

Silicon has a large impact on the energy supply and economy in the modern world. In industry, high purity silicon is firstly prepared by carbothermic reduction of silica with the produced raw silicon being further refined by a modified Siemens method. This process suffers from the disadvantages of high cost and contaminant release and emission. As an alternative, the molten salt electrolysis approach, particularly the FFC Cambridge Process (FFC: Fray-Farthing-Chen), could realize high purity silicon products with morphology-controllable nanostructures at low or mild temperatures (generally $650-900{ }^{\circ} \mathrm{C}$ ). In this article, we review the development, reaction mechanisms, and electrolysis conditions of silicon production by the FFC Cambridge Process. Applications of the silicon products from electrolysis in molten salts are also discussed in terms of energy applications, including using them as the photovoltaic element in solar cells and as the charge storage phase in the negative electrode (negatrode) of lithium ion batteries. 
Keywords: Electrolysis; Molten salt; Silicon; Nanomaterial; Li ion battery; Solar cell

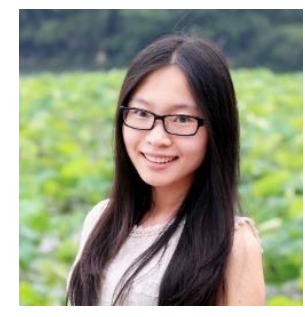

Tingting Jiang (ORCID: 0000-0002-6924-7613) received her BSc in Materials Science and Engineering from Zhejiang University in 2009, and her $\mathrm{PhD}$ in materials physics and chemistry from Zhejiang University and State Key lab of Silicon Materials in 2014. Currently, she is an associate professor at Wuhan University of Science and Technology. Her research interests are designs and mechanisms of high-capacity lithium ion battery electrode materials and electrochemical production and properties of silicon-based materials in molten salts.

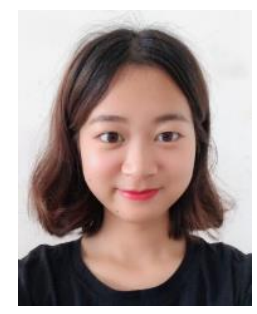

Xinyi Xu obtained her bachelor's degree in Civil Engineering from Anhui University of Science and Technology in 2016. She then began her MSc degree in Materials Engineering at Wuhan University of Science and Technology in 2018. Currently, she is engaged in electrochemical research, aiming at the application of silicon-based materials in the negative electrode of lithium ion batteries.

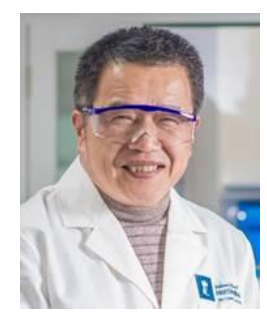

George Z. Chen (ORCID: 0000-0002-5589-5767) graduated from Jiujiang Teachers Training College with a Diploma in 1981, Fujian Normal University with the MSc in 1985, and the University of London with the PhD and DIC in 1992. After contracted work in the Universities of Oxford, Leeds and Cambridge, he joined the University of Nottingham in 2003, became Professor in 2009. He is also Li Dak Sam Chair Professor of the University of Nottingham Ningbo China, and Specially Invited Professor of Wuhan University of Science and Technology. His research aims at electrochemical and liquid salts innovations for materials, energy and environment with research supports from various sources, such as the Schlumberger Interdisciplinary Fellowship (Darwin College Cambridge), Cheung Kong Scholarship (MoE of China), Distinguished Young Scholars Fund (NSFC), Brian Mercer Feasibility Award (Royal Society), International Energy Research Award (E.ON AG), REFINE Consortium (EPSRC), and the 3315 Plan for Innovation Team (Ningbo City). 


\section{Introduction}

Silicon is the second most abundant element in the Earth's crust (about $28 \%$ by mass) after oxygen. It is most widely distributed in dusts and sands as various forms of silicon dioxide (silica) or silicates. It has a large impact on the modern world economy because of its wide use in steel refining, aluminum-casting, and fine chemical industries Of equal importance, a relatively small portion of highly purified elemental silicon is used in semiconductors $(<10 \%)$ which are essential to integrated circuits on which most computers, cell phones, and other modern technologies depend. Silicon also plays critical roles in clean-energy devices such as solar cells and lithium-ion batteries (LIBs). Monocrystalline and polycrystalline silicon solar cells have dominated the commercial photovoltaic technology since early 1940s. On the other hand, silicon is one of the most promising candidates for the new generation of negative electrodes (negatrodes) in LIBs due to its relatively negative discharging potential and high specific charge capacity, $Q_{\mathrm{sp}}=\frac{n F}{\left(M_{S i}+n M_{L i}\right)}=2112 \mathrm{mAh} \mathrm{g}^{-1}$, considering both the masses of silicon, $M_{\mathrm{Si}}$, and lithium, $M_{\mathrm{Li}}$, in the negatrode reaction of $\mathrm{Si}+n \mathrm{Li}^{+}+n \mathrm{e}=\mathrm{SiLi}_{n}$, where $n=4.4$. (Note that the widely reported value of $4200 \mathrm{mAh} \mathrm{g}^{-1}$ is calculated ignoring the mass of lithium, which is inappropriate in theory and also in practice.)

At present, high-purity quartz is the main raw material for industrial preparation of silicon, usually by carbothermic reduction. The received silicon has a purity less than 99\%, called metallurgical grade silicon (MG-Si). The MG-Si is further purified by a modified Siemens method, resulting in the so called solar grade silicon (SOG-Si) feedstock with purity of $6 \mathrm{~N}(99.9999 \%)[1,2]$. The disadvantages of this process are 
the high cost and significant release and emission of contaminants. As for the silicon material used in the negatrode of LIBs, the most common production methods are magnesiothermic reduction, chemical vapor deposition (CVD) or chemical etching [37], which are all difficult to realize at large-scales.

The molten salt electrolysis approach could realize both silicon purification and silicon nanomaterial preparation, owning to many merits [8]. Massive preparation of silicon nanomaterials can be realized at lower temperatures (generally $650-900{ }^{\circ} \mathrm{C}$ ). Meanwhile, during the electrolysis process in molten salt, $\mathrm{SiO}_{2}$ can be reduced into size-, purity- and morphology-controllable silicon products. Compared to the traditional carbothermic reduction method, the FFC Cambridge Process shows several advantages which are summarized in Table 1. Although it is not yet in operation to produce silicon at the industrial scale by the FFC Cambridge Process, the scale-up pilot of the semi-continuous electro-reduction of $\mathrm{SiO}_{2}$ to nano-silicon wires in molten salt has been successful in Beijing (http:/www.glabat.com/) for the LIB negatrode application. In principle, the FFC Cambridge Process can be scaled up for either batch or continuous operations, depending on needs. This is because the reactant and product in the FFC Cambridge Process are both solids on the cathode, whilst the electrolyzer can have multiple cathodes, which can then be inserted and removed alternatively, leading to the same effect as a continuous process.

In this paper, electrolytic production of silicon in molten salts by the FFC Cambridge Process is selectively reviewed. The fundamental reaction mechanism, and the research and technology development are presented, and then the specific 
conditions in the electrolysis reaction are discussed. At last, the application outlook of the molten salts enabled electrolytic silicon in existing and new energy fields is introduced, such as the photovoltaic element in solar cells and the charging-discharging responsive phase in the negatrode of LIBs.

Table 1. Comparison between the traditional carbothermic reduction process and the FFC Cambridge Process.

\begin{tabular}{lll}
\hline & Carbothermic reduction process & FFC Cambridge Process \\
\hline Purity & $>99 \%$ & $99.99 \%$ \\
Energy consumption & $13 \mathrm{KWh} \mathrm{kg}^{-1}$ & $9.3 \mathrm{KWh} \mathrm{kg}^{-1}$ \\
& Mature, large-scale & $\begin{array}{l}\text { Zero or low emission, } \\
\text { high energy efficiency }\end{array}$ \\
Advantages & High energy consumption, \\
high cost, high $\mathrm{CO}_{2}$ emission & $\begin{array}{l}\text { In development for } \\
\text { commercial production }\end{array}$ \\
\hline
\end{tabular}

\section{Mechanism of electrochemical reduction in molten salts}

\subsection{Electrochemical reaction process in electro-reduction of silicon dioxide}

Since late 1940 s, the titanium metal has been dominantly produced by smelting $\mathrm{TiO}_{2}$-rich ore at high temperatures via the Kroll process [9]. Since titanium is very active at high temperatures and easy to combine with oxygen, nitrogen, carbon and other elements, purification of titanium can only be conducted in very strict conditions. In 2000, Chen et al. [10] proposed a new method to prepare titanium from $\mathrm{TiO}_{2}$ powders.

They successfully prepared metallic titanium by electrolysis of solid $\mathrm{TiO}_{2}$ in molten $\mathrm{CaCl}_{2}$. This method was also found to work with the preparation of other metals and semi-metals from their solid compounds, particularly oxides, and has been then called the FFC Cambridge Process in which FFC is from the names of the inventors, 
Fray, Farthing and Chen. In this method, the oxide which is often non-conductive is usually used to make the cathode, such as $\mathrm{TiO}_{2}$ and $\mathrm{SiO}_{2}$. A typical schematic diagram of this process in laboratory is shown in Fig. 1 in which the oxide is made into a porous precursor (e.g. pellet) wrapped with nickel mesh and molybdenum wire to form the cathode. The commonly used anode is a graphite rod. The electro-reduction is carried out in different molten salts to prepare different elementary substances. $\mathrm{CaCl}_{2}$ or its mixture with other alkali and alkaline earth chlorides are the most used to prepare the molten salts with low viscosity, high ionic conductivity and easy movement of ions after melting. When a voltage is applied between the anode and cathode, an electric current is generated, assisted by the movement of ions in the molten salts, which causes electrochemical reactions at the electrodes. In traditional electrolysis of a molten salt containing dissolved metal ions, deposition of the metal occurs at the cathode. However, in the FFC Cambridge Process, the molten salt contains no dissolved ions of the metal to be produced. Instead, the cathode reaction is the direct reduction of the solid metal compound, e.g. oxide or sulfide, to the metal.

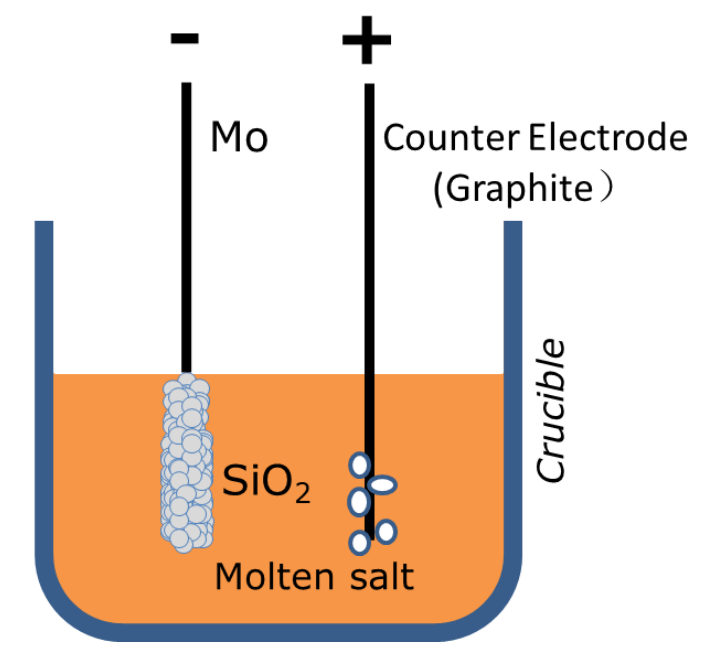


Fig. 1. Schematic diagram of the laboratory cell for the FFC Cambridge Process.

Since then, the FFC Cambridge Process has been widely used to extract or purify some rare metals, such as titanium [11, 12], tantalum [13], niobium [14], zirconium[15, 16], and uranium [17]. The FFC Cambridge Process also provides a new idea for the preparation of elemental silicon. In 2003, Nohira et al. [18] first reported their observation of elemental silicon in electrolysis of quartz (silica) plates in molten $\mathrm{CaCl}_{2}$. Fig. 2(a and c) shows two types of contacting electrodes used in this work, and Fig. 2(b and d) is the corresponding photographs after electrolysis under different conditions. It can be seen that elemental silicon was produced on the surface of the quartz plate after electrolysis, and the sample in Fig. 2(b) exhibited a more completed reaction due to the larger metal-quartz contact area.

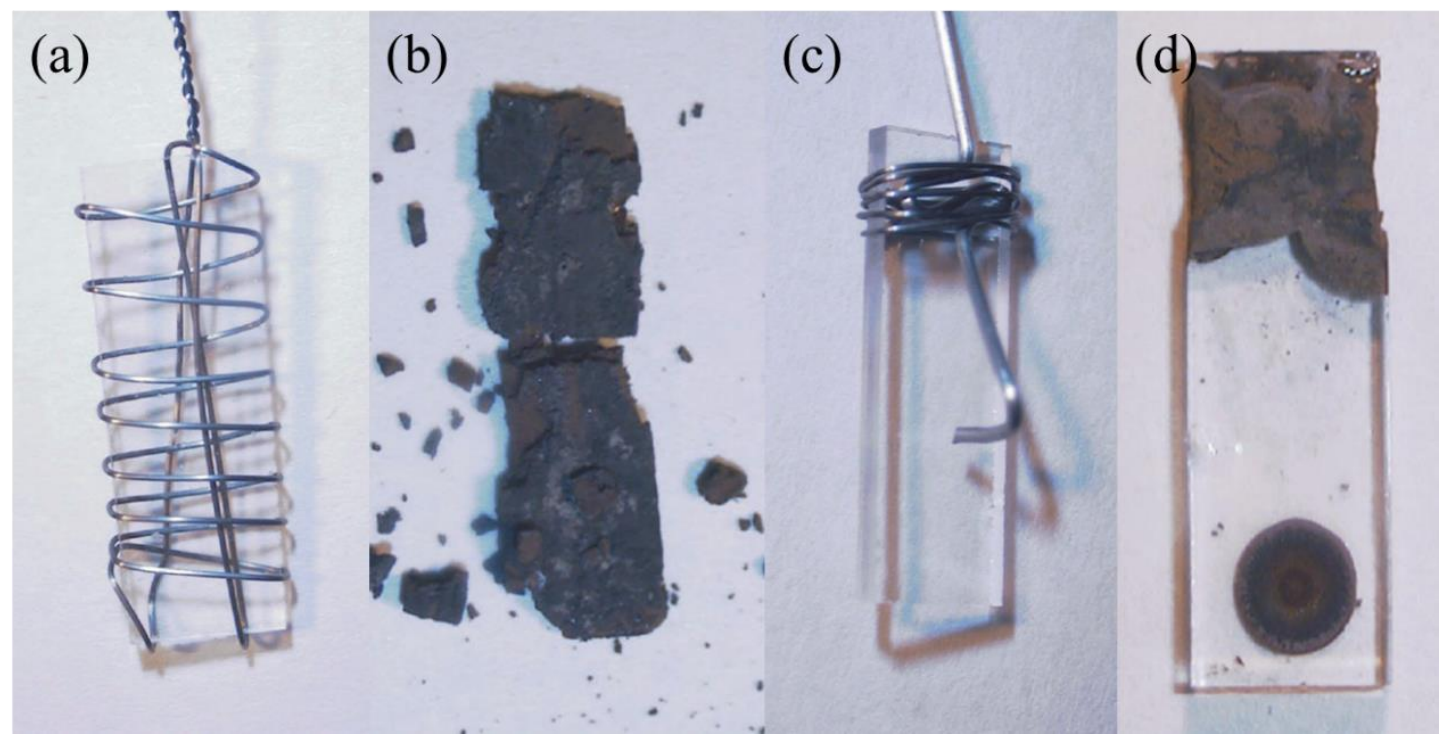

Fig. 2. Photographs of the two types of contacting electrodes: (a) Type A: a molybdenum wire is wound round the quartz plate about ten times. (b) Type A was electrolyzed at $0.7 \mathrm{~V}$ potentials in molten $\mathrm{CaCl}_{2}$ at $850^{\circ} \mathrm{C}$ for $1 \mathrm{~h}$. (c) Type B: the quartz plate is point-contacted with a sharp-edged molybdenum wire at the middle of the plate, 
and wound round by a molybdenum wire at the top of the plate. (d) Type B was electrolyzed at $0.7 \mathrm{~V}$ potentials in molten $\mathrm{CaCl}_{2}$ at $850{ }^{\circ} \mathrm{C}$ for $15 \mathrm{~min}$. Reprinted from Ref. [18], with the permission of Springer Nature.

They also studied the electrode reactions as follows:

$$
\begin{aligned}
& \text { Anode: } 2 \mathrm{O}^{2-} \rightarrow \mathrm{O}_{2}+4 \mathrm{e}^{-} \\
& \text {Cathode: } \mathrm{SiO}_{2}+4 \mathrm{e}^{-} \rightarrow \mathrm{Si}+2 \mathrm{O}^{2-} \\
& \text { Overall reaction: } \mathrm{SiO}_{2} \rightarrow \mathrm{Si}+\mathrm{O}_{2}
\end{aligned}
$$

The reaction process can also be represented by the cyclic voltammograms (CVs) in Fig. 3.
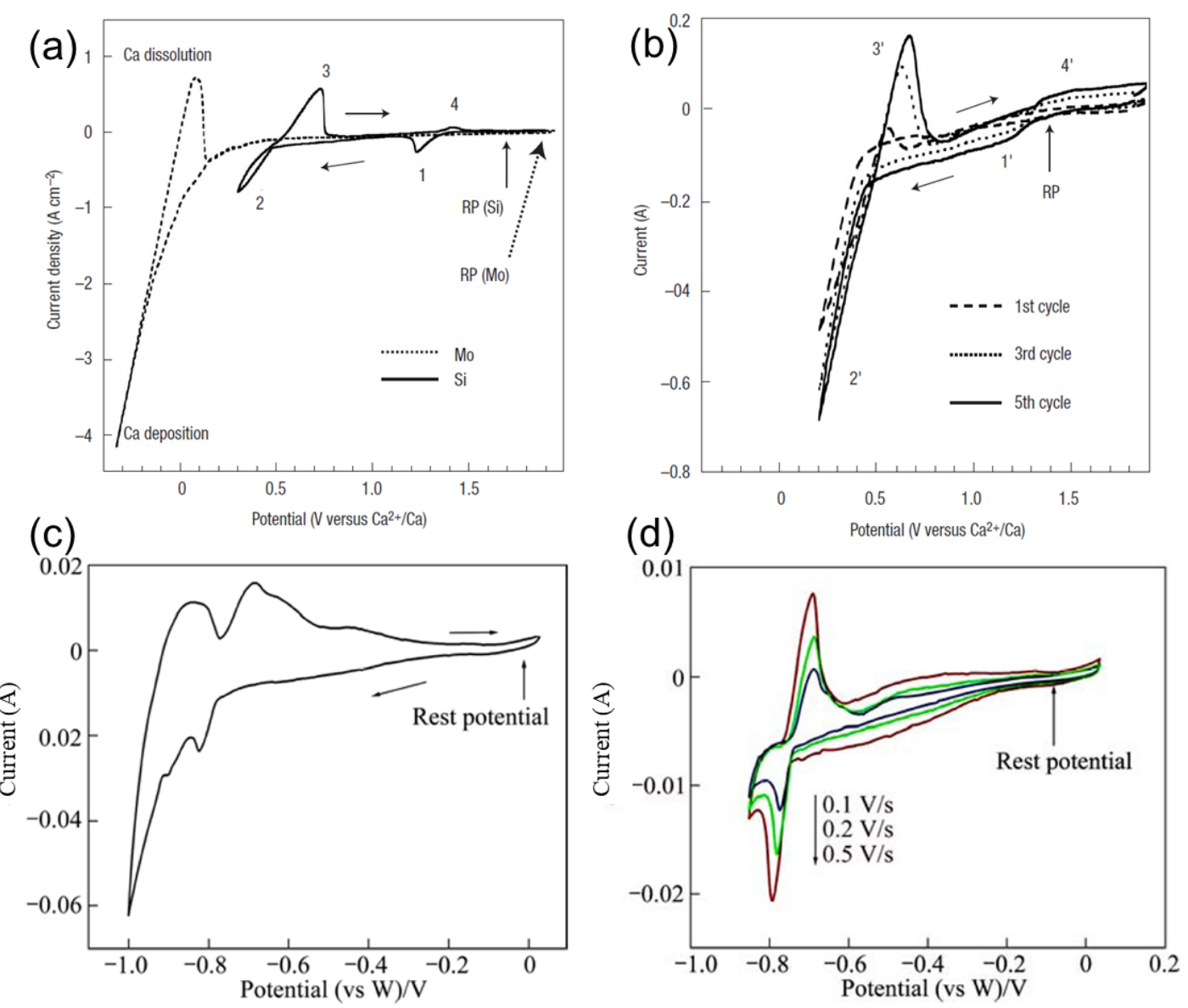
Fig. 3. (a) $\mathrm{CVs}$ of $\mathrm{Mo}, \mathrm{Si}$ and $\mathrm{SiO}_{2}$ contacting electrodes in molten $\mathrm{CaCl}_{2}$ at $850{ }^{\circ} \mathrm{C}$. Mo wire (1 $\mathrm{mm}$ in diameter, $1 \mathrm{~cm}$ in depth in electrolyte) and single-crystal Si plate (1 $\mathrm{cm}^{2}$ in electrolyte). (b) $\mathrm{SiO}_{2}$ contacting electrode (type A). The potential scan rate was $0.02 \mathrm{~V} \mathrm{~s}^{-1}$. RP is rest potential. Reprinted from Ref. [18], with the permission of Springer Nature. (c) $\mathrm{CVs}$ at $1123 \mathrm{~K}$ in molten $85 \% \mathrm{CaCl}_{2}-5 \% \mathrm{NaCl}-5 \% \mathrm{CaO}-5 \% \mathrm{Si}$ in mole fraction. (d) $\mathrm{CVs}$ with varying sweep rates at $1123 \mathrm{~K}$ in molten $85 \% \mathrm{CaCl}_{2}-5 \%$ $\mathrm{NaCl}-5 \% \mathrm{CaO}-5 \% \mathrm{Si}$ in mole fraction. (Tungsten electrodes) Reprinted from Ref. [19], with the permission of Elsevier.

Fig. 3( $a$ and $b$ ) shows the CVs of the molybdenum wire, monocrystalline silicon and silicon dioxide contact electrode at a scanning speed of $0.02 \mathrm{~V} \mathrm{~s}^{-1}$. Fig. 3(a) shows the current of calcium dissolution and deposition. Peak 2 and 3 were thought to have resulted from the formation of the calcium silicon alloy $(0.35 \mathrm{~V})$ and deformation respectively, which were confirmed by XRD analysis. Peaks 1 and 4 were attributed to the surface reduction of silicon oxide to silicon and re-oxidation of the silicon. Similarly, in Fig. 3(b), peaks 2' and 3' to the formation and deformation of Si-Ca alloy, and peaks 1' and 4' are attributed to the reduction of silica and oxidation of silicon, respectively. In addition, the peak value increases with the increase of scanning times, indicating the increase of reaction interface. Also, by conducting constant potential electrolysis, it has been demonstrated that electro-reduction of silica could occur at $1.1 \mathrm{~V}$ vs. $\mathrm{Ca}^{2+} / \mathrm{Ca}$ or more negative potentials.

In order to purify the metallurgical grade silicon by electrorefining, Cai et al. [19] performed electrolysis by means of a liquid alloy anode of silicon and copper in molten 
calcium chloride-sodium chloride-calcium oxide-silicon mixture (85:5:5:5 in mole fraction). Similar CVs were obtained, which are shown in Fig. 3(c and d). The potential for the formation of dissolved calcium is less than the reversible potential for calcium deposition, with the potential range from $-0.2 \mathrm{~V}$ (vs. W) in which the cathodic current increases steadily. Dissolved calcium is known to exist as a divalent species, $\mathrm{Ca}_{2}{ }^{2+}$. The cathodic reaction is likely to be:

$$
2 \mathrm{Ca}^{2+}+2 \mathrm{e}^{-} \rightarrow \mathrm{Ca}_{2}{ }^{2+}
$$

The cathodic and anodic current peaks at approximately $-0.8 \mathrm{~V}$ and $-0.7 \mathrm{~V}$ are due to the deposition and dissolution of silicon respectively. After the deposition of silicon, the deposition of calcium caused the increased of cathodic current, the calcium is oxidized in the return scan and shown as a current peak at around - 0.85 V. In Fig. 3(d), it can be seen that the peak becomes more and more obvious with the increase of scanning speed at the scanning potential range from $0 \mathrm{~V}$ to $-0.85 \mathrm{~V}$, which is related to the anodic oxidation of dissolved calcium and the diffusion and reaction of dissolved silicon complexes on the return scan.

The process of electro-reduction of silicon dioxide to elemental silicon by accepting electrons was also studied by AC impedance spectroscopy, and the findings suggested that the process could be divided into two steps [20]. The two reduction peaks on the CVs also suggested intermediate products of the process, which were revealed by XRD to be fairly complex, such as $\mathrm{SiO}, \mathrm{CaSiO}_{3}$, and $\mathrm{CaSiO}_{4}$.

\subsection{Mechanism of silicon crystal growth in electrochemical reduction process in molten salt}




\subsubsection{Models of crystal growth mechanism}

According to 2.1, electrons transfer happens in two steps in reduction reaction of electrolyzing silicon dioxide in molten salt. During the reduction process, $\mathrm{SiO}_{X}$ provides condition for the subsequent growth of elemental silicon other than acting as the intermediate in the reaction system.

Yasuda et al. [20] studied the reaction process of the electro-reduction of $\mathrm{SiO}_{2}$ in molten salt, and the atomic structure diagram can be seen in Fig. 4. Unlike other simple substances prepared by electrolysis, $\mathrm{SiO}_{2}$ is insoluble in the electrolyte. At the beginning of the reaction in Fig. 4(a), silicon and oxygen atoms are connected by $\mathrm{Si}-$ $\mathrm{O}-\mathrm{Si}$ bridge bonds. As soon as the electrolytic deoxidation begins (Fig. 4b), $\mathrm{Si}-\mathrm{O}$ bonds start to break, oxygen atoms obtain electrons and move into the electrolyte, leaving silicon atoms with dangling bonds as a kind of intermediate state. Then, these intermediates recombine with neighboring silicon atoms in a very short time to form amorphous silicon (Fig. 4c). At high temperatures, amorphous silicon may transfer into crystalline silicon via atomic rearrangement. The reduction of $\mathrm{SiO}_{2}$ to amorphous silicon is believed to be the most crucial step in the whole reaction. 
(a)

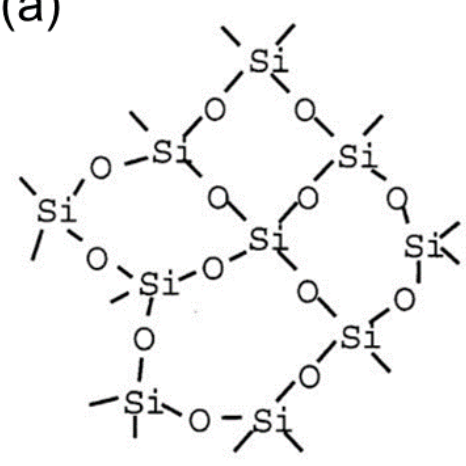

(c)

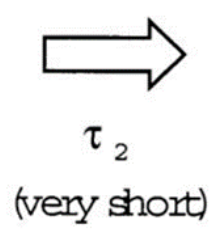

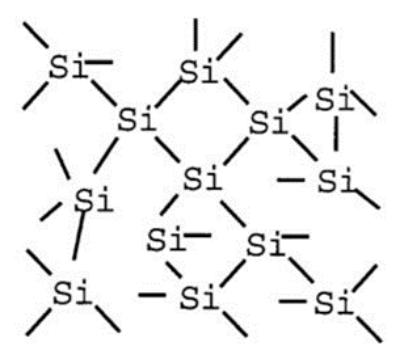

(b)

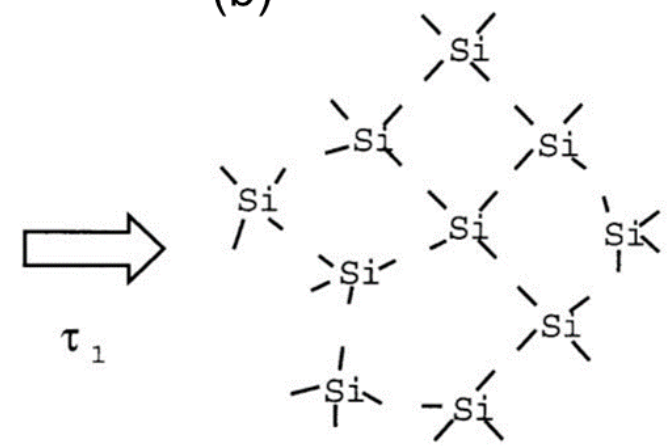

(d)

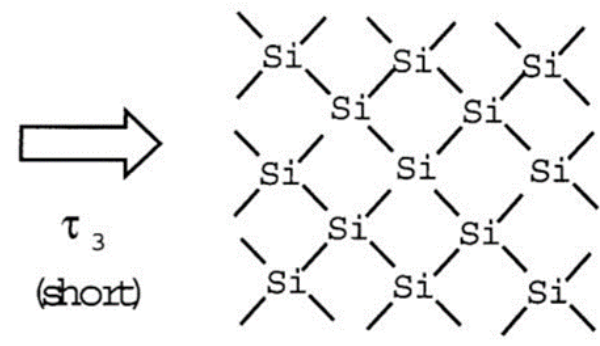

Fig. 4. The atomic structure diagram in the reaction process. (a) The original $\mathrm{SiO}_{2}$, (b) Si immediately after reduction, (c) a-Si, and (d) c-Si during the electro-reduction of solid $\mathrm{SiO}_{2}$ to $\mathrm{Si}$ in molten $\mathrm{CaCl}_{2}$ at $1123 \mathrm{~K}$. Reprinted from Ref. [20], with the permission of Electrochemical Society.

Chen et al. [21] proposed the metal/metal oxide/molten salt three phase interline (3PI) propagation (Penetration-3PI) model in electrolytic preparation of chromium. In 2004, Jin et al. [22] reported the electroreduction of silica in molten salt, which is in accordance with the 3PI propagation model. According to Chen's three-phase boundary reaction model, the reaction speed along the radial direction is much faster than that along the axial direction. Fig. 5(a and b) schematically illustrates the typical reduction process for silicon dioxide in 3PI propagation mechanism [23]. In the FFC Cambridge Process, the reaction on the cathode includes three phases: the metal, the metal oxide 
and the molten salt. To reduce the oxide, electrons and oxygen ions would transfer from the metal to the oxide and from oxide to the electrolyte respectively. Jin et al. [22] studied the relationship between the depth and time of reduction of solid $\mathrm{SiO}_{2}$ in molten calcium chloride. The electrode used was a $\mathrm{SiO}_{2}$ wrapped $\mathrm{W}$ wire or the $\mathrm{W}-\mathrm{SiO}_{2}$, and the obtained results satisfied well with the 3PI model. As shown in Fig. 5(a), the reduction of $\mathrm{SiO}_{2}$ in contact with the $\mathrm{W}$ wire begins at the metal/ $/ \mathrm{SiO}_{2} / \mathrm{molten}$ salt $3 \mathrm{PIs}$ and as soon as silicon is generated, a new $\mathrm{Si} / \mathrm{SiO}_{2} / \mathrm{molten}$ salt $3 \mathrm{PI}$ forms. Then, the $3 \mathrm{PIs}$ develop with the reduction process to the end surface of the electrode, resulting in the completion of surface metallization. After that, the reduction occurs along the 3PIs both in the radial and depth directions until the electro-reduction of the bulk oxide electrode proceeds completely. The $\mathrm{Si} / \mathrm{SiO}_{2} /$ molten salt $3 \mathrm{PIs}$ still exist inside the electrode. As seen in Fig. 5(b), the inward propagating 3PI from the outer surface will decrease in length while the outward propagating 3PI from the central hole will increase in length. Therefore, the 3PI length could keep constant approximately, leading to the current plateau until the full metallization of the pellet. Fig. 5(c,d) shows the SEM images of the $\mathrm{W}-\mathrm{SiO}_{2}$ electrode before and after the first $\mathrm{CV}$ cycle, and Fig. 5(d) displays a ring of porous product, which is in good accordance with the reduction process in the 3PIs model. 

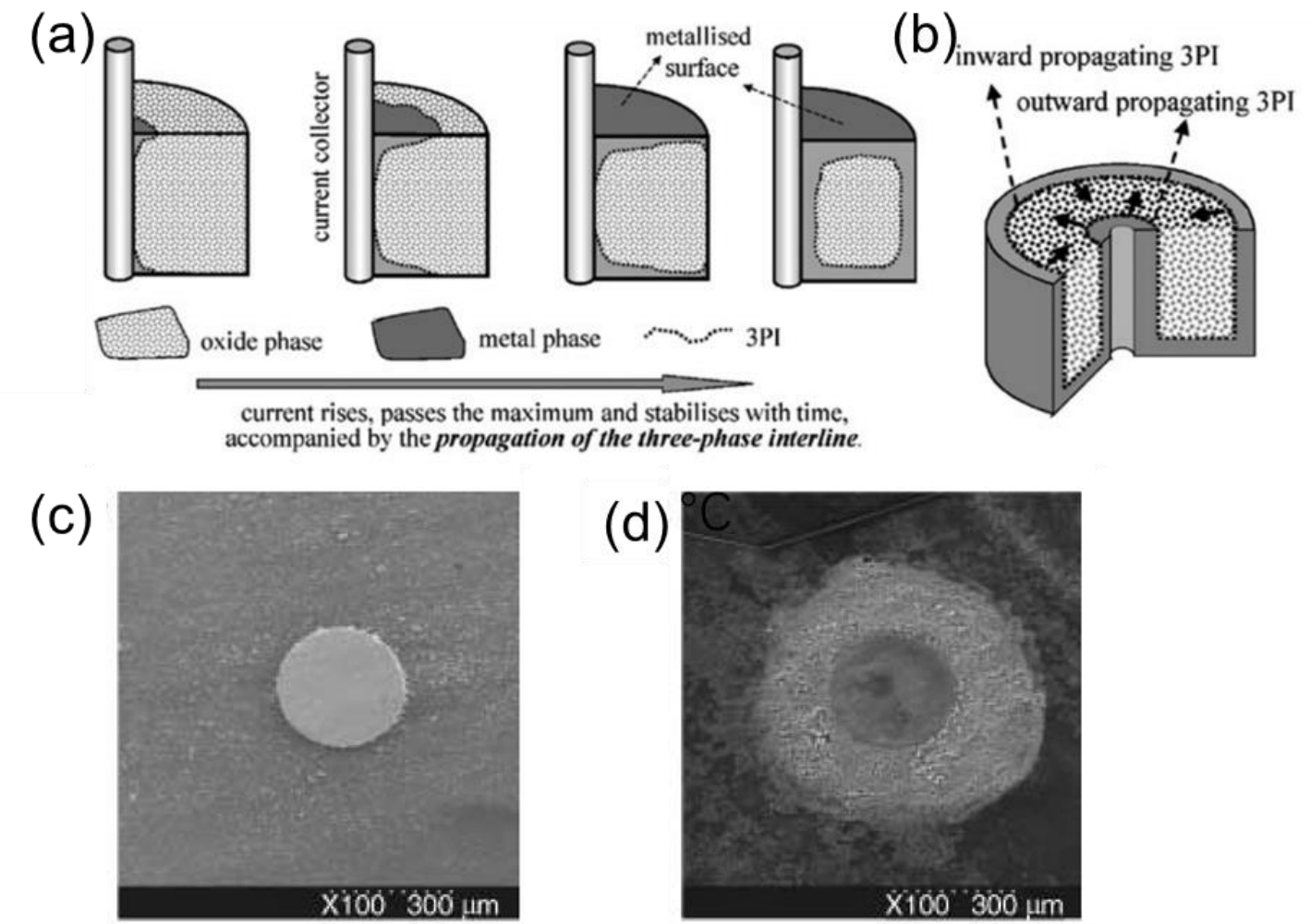

(b) inward propagating 3PI

(c)

(d)

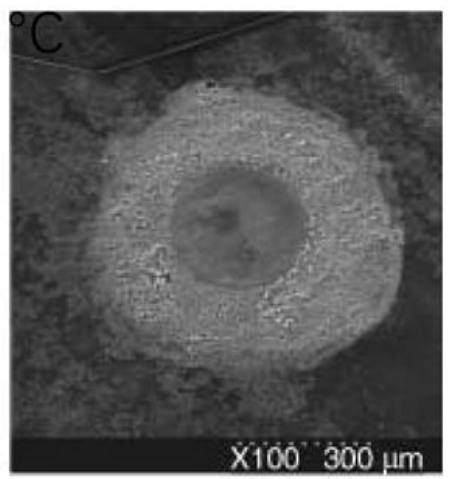

(e)
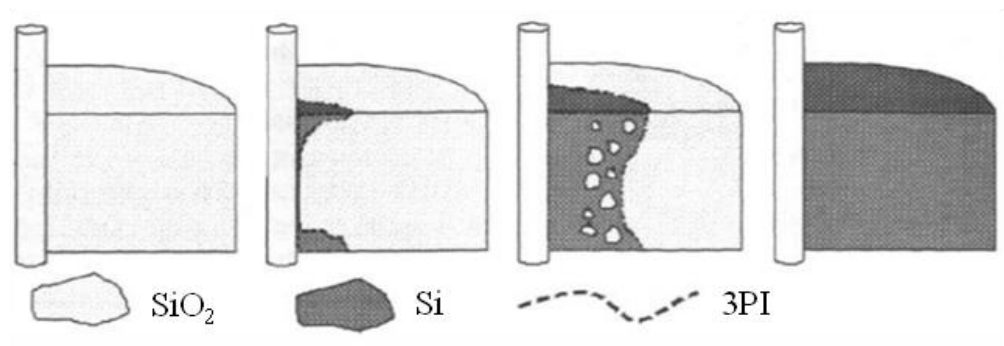

Fig. 5. Schematic illustration of the 3PI propagation mechanism for electrochemical reduction of a cylindrical oxide pellet. (a) The 3PI propagating from the central wire along the surface; (b) The 3PI propagating within the pellet. Reprinted from Ref. [23], with the permission of Springer Nature. SEM images of the $\mathrm{W}-\mathrm{SiO}_{2}$ electrode before (c) and after (d) one cycle of potential sweep. Reprinted from Ref. [22], with the permission of John Wiley and Sons. (e) Schematic illustration of the three-phase interlines (3PI) propagation mechanism for the electrochemical reduction of nanometer silica pellets. (Copyright 2009 Yang.) Reprinted from Ref. [25], with the permission of Chinese Journal of Inorganic Chemistry. 
In addition to the above theory, Yang et al. [24,25] proposed a three-phase interface (actually three-phase interline) mechanism, in which the reaction was uniformly moved along the radial direction of the electrode plate. The reaction mechanism diagram of the three-phase interface is shown in Fig. 5(e). According to their report, the reaction occurred initially at the contacting interface between the metal and $\mathrm{SiO}_{2}$ in molten $\mathrm{CaCl}_{2}$, and then moved radically, and which is the so-called "model of three phase interface". As the reaction proceeds, the inner part of the electrode is mainly a pure product of silicon. Moreover, silicon dioxide can be observed in the outer surface layer. Energy dispersive spectroscopy (EDS) measurement also demonstrated the existence of $\mathrm{SiO}_{2}$ in the sub-inner layer.

\subsubsection{Growth of silicon nanowires}

Except for silicon powder, Yang et al. [24], Nohira et al. [26] and others [27-29] all obtained silicon nanowires (SiNWs) via electro-reduction in molten salt by verifying the reaction parameters. Here we conclude the relative growth process, relations to the final morphology and then the growth mechanism of silicon nanowires.

Fig. $6(a, b)$ shows the nucleation and growth mechanism of SiNWs. According to Yang et al. [24], firstly, silica in the molten salt may melt or be dissolved. As long as the electrode potential satisfy the reduction potential of silica, silica can be reduced firstly on the molybdenum conductive wire (metal current collector)/molten silica/molten salt three-phase interface to form nano-sized silicon. These nano-sized silicon seed crystals are apart from each other at the beginning (Fig. 6a). Due to the good conductivity of silicon at high temperature, the new-generated silicon seed crystal 
can form the new three-phase electrochemical reaction interface with the remaining molten silicon dioxide and calcium chloride molten salt. As the development of 3PIs, molten $\mathrm{CaCl}_{2}$ can insert on the silica interface and most silica can be reduced to silicon, resulting the SiNWs growth (Fig. 6b). Moreover, with the prolongation of the reaction time, the reaction proceeds more rapidly as the active interface moves towards three dimensions. The corresponding SEM images of samples electrolyzed for different times shown in Fig. 6(c and d) prove the above growth mechanism of SiNWs. At high temperature, amorphous silicon then converts to crystalline silicon. Nucleation and crystal growth steps repeat to form SiNWs with complete structures. The most important thing is that the reaction interface is uniformly pushed along the radial direction of the electrode plate until the reaction of the whole electrode plate is completed. 
(a)
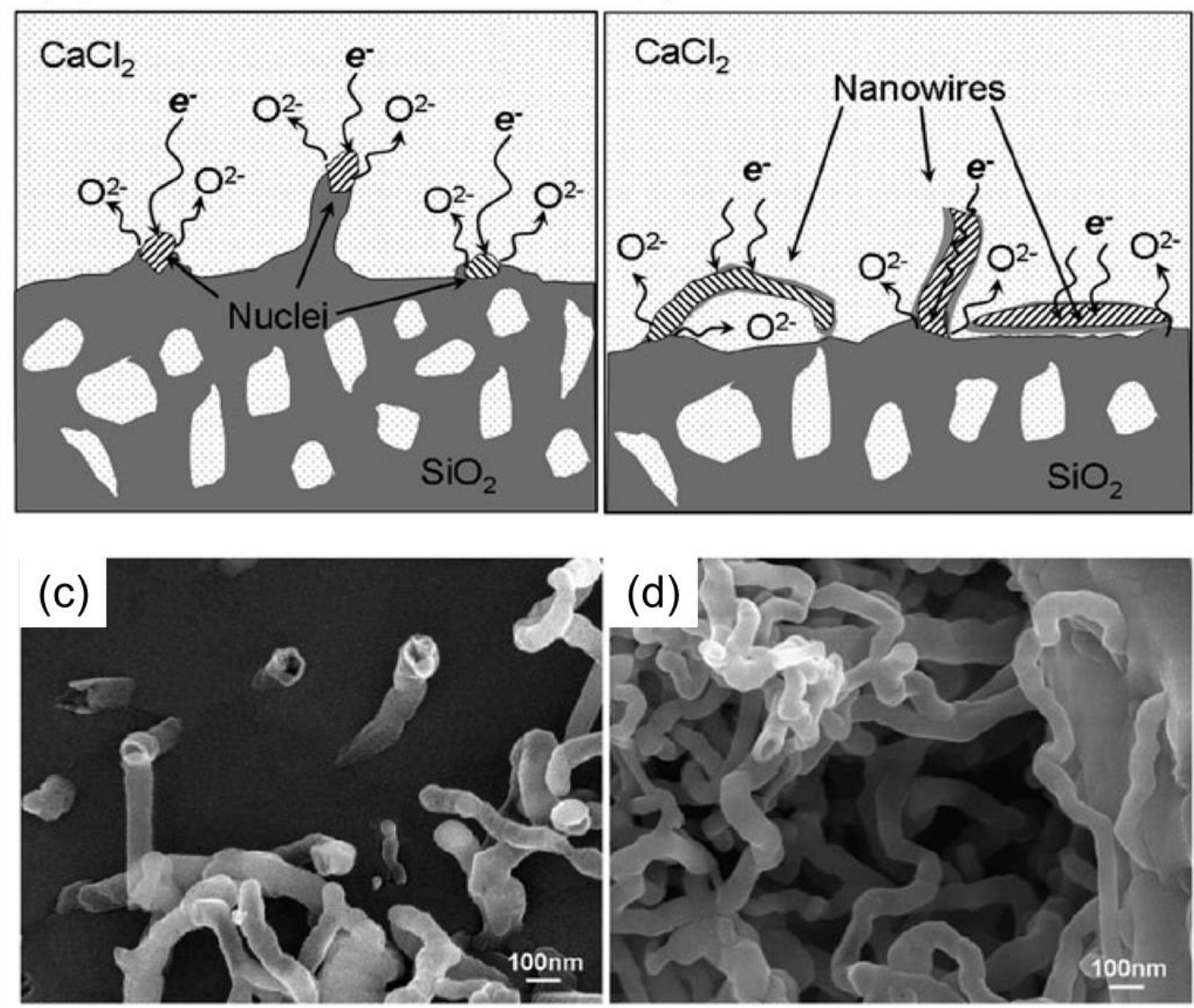

(e)

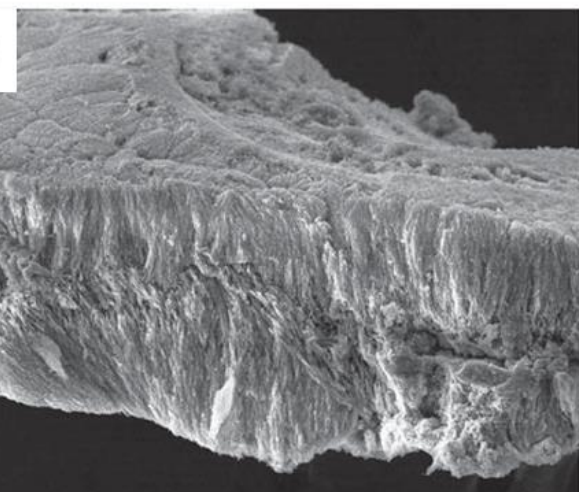

$200 \mu \mathrm{m}$

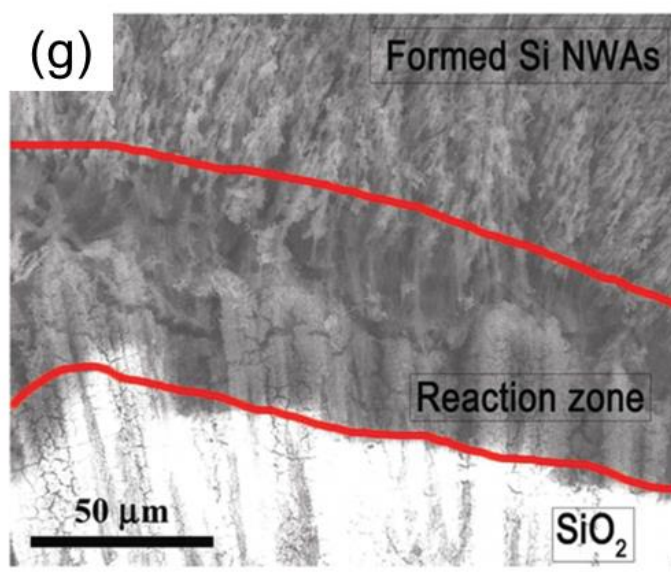

(b)
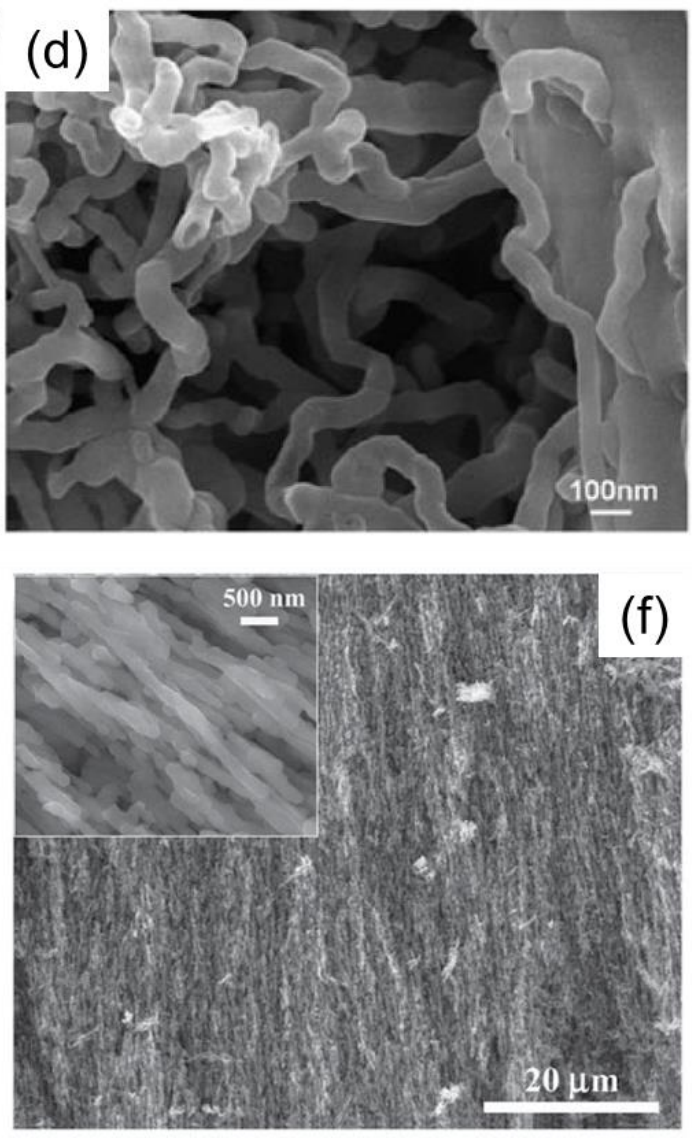

(h)

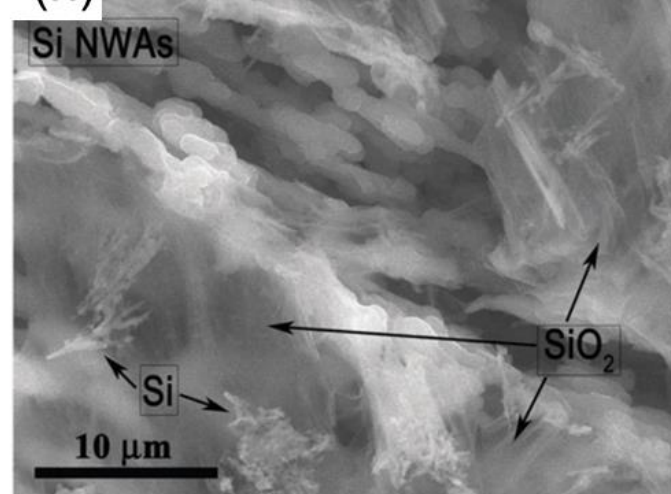


Fig. 6. Schematics of the growth mechanism of SiNWs by electrochemical process in molten $\mathrm{CaCl}_{2}$. (a) nucleation, (b) growth. Cross-sectional FESEM images of samples electrolyzed for (c) $5 \mathrm{~min}$, (d) 15 min. Reprinted from Ref. [24], with the permission of Royal Society of Chemistry. SEM images of the freestanding SiNW arrays (e) in low magnification oblique view, (f) side view. (g) The reaction zone in side view in low magnification. (h) The reaction zone in higher magnification. Reprinted from Ref. [27], with the permission of Royal Society of Chemistry.

The growth is continuous in the axial direction of the SiNWs, but not in the lateral direction. In 2013, Zhao et al. [27] synthesized freestanding SiNW arrays by electroreduction of $\mathrm{SiO}_{2}$ in molten $\mathrm{CaCl}_{2}$. As can be seen in Fig. 6(e and f), the $\mathrm{SiNW}$ arrays with a thickness around several hundreds of micrometers are consisted of nanowires with different diameters (50-200 nm). They proposed that in the reaction process [30], the soft melted silicon dioxide moves to the SiNWs which connected with the surface of silicon dioxide and reacts to generate new SiNWs. The nanowires grew from the outer surface towards the inside and aligned vertically to the surface. In addition, the morphology and composition of the product can be controlled by controlling the potential [30].

By investigating the morphology of the intermediate products in the reaction, it is suggested that the growth mechanism of SiNW arrays is a self-assembling process. Fig. $6(\mathrm{~g})$ shows a reaction region found between the as-grown SiNWs and the remaining $\mathrm{SiO}_{2}$, in which the $\mathrm{Si}$ atom ratio gradually decreases from 1 to $1 / 3$. The thin-silk like $\mathrm{SiO}_{2}$ and silicon nano particles can be observed in the region (Fig. 6h). During the 
reaction, the thin-silk $\mathrm{SiO}_{2}$ would wrap the silicon nano particles and moves to the formed silicon nanowires together to finish the whole reduction process.

However, to date the mechanism of growing process of SiNWs in electroreduction has not been very clear and needs more exploration. More accurate conclusions will be drawn on this issue in the future.

\section{Effect of electrolysis conditions on final product}

Based on the mechanism discussed in section 2, researchers have successfully prepared silicon with various morphology and purity by electro-reduction in molten salt. By modifying the reaction conditions, including reduction potential, starting material (silicon dioxide), molten salt and so on, the crystalline SiNWs and nanoparticles of a high purity can be obtained. The received silicon nanomaterials are in high demand, which can further be used in energy applications, such as LIBs and solar cells. Compared to the carbothermic reduction of $\mathrm{SiO}_{2}$, which is the most-used current producing technique, electro-reduction in molten salt shows the advantages of less carbon releasing, less energy consumption and less thermal releasing. The received silicon always has a higher purity in an easier process. The reaction process can also be controlled by constant current, which is easy to realize continuous production and can significantly reduce the cost. Thus, it has gained extensive attention from both academic and industrial community.

\subsection{Starting materials}

It is well known that the purity and morphology of starting materials have a great 
influence on chemical reactions. In this section, starting materials including molten salts, silicon dioxide, and addition reactants with different types, morphologies and purities will be discussed. They significantly affect the reaction rate, the morphology of reaction products and their properties as well.

\subsubsection{Molten salts}

As one of the most used molten salt, calcium chloride is a typical ionic compound with good solubility in water and is conductive to subsequent reduction. Other molten salts including alkali metal molten salts, metal fluoride and chloride coupling molten salts are also in common use. Besides, chloride mixtures with different molar ratios can also be used as molten salts. Types and composition ratio of molten salt mainly affect the reaction temperature as a result of different melting point.

According to Nohira et al. [18], electrochemical methods for removing oxygen from solid $\mathrm{SiO}_{2}$ in a molten $\mathrm{CaCl}_{2}$ electrolyte can be conducted at $850{ }^{\circ} \mathrm{C}$. Meanwhile, the temperature will decrease to $500{ }^{\circ} \mathrm{C}$ when the same method was demonstrated with molten LiCl-KCl-CaCl 2 .

In 2013, Tokushige et al. [31] used lithium chloride (purity 99.9\%): potassium chloride (purity $99.5 \%$ ) with a ratio of $41.5 \%: 58.5 \%$ as molten salt and silica powder as starting material. The melting point of molten salt is $352{ }^{\circ} \mathrm{C}$ and the reaction temperature is $450{ }^{\circ} \mathrm{C}$. Silicon nanoparticles with a diameter of about $20 \mathrm{~nm}$ were achieved. During the reaction process, impurities like silicon carbide were found in the final product due to the carbonate ions in the molten salt and the usage of carbon anode. Based on Faraday's law, the current efficiency of this reaction is $70 \%$. 
Ergül et al. [32] realized the direct electrochemical reduction of porous $\mathrm{SiO}_{2}$ pellets in molten $\mathrm{CaCl}_{2}$ salt and $\mathrm{CaCl}_{2}-\mathrm{NaCl}$ salt mixture. Two different molten salts were used. For pure calcium chloride, the reaction kept at $850^{\circ} \mathrm{C}$, while for calcium chloride/sodium chloride mixture (with a molar ratio of 7:3), the reaction temperature varied from $750{ }^{\circ} \mathrm{C}, 800{ }^{\circ} \mathrm{C}$ and $850{ }^{\circ} \mathrm{C}$, respectively. They found that the addition of $\mathrm{NaCl}$ to the electrolyte decreased the accumulative charge passing through the cell and therefore decreased the reduction rate.

In conclusion, the molten salts containing $\mathrm{CaCl}_{2}$ are usually utilized in electroreduction of silicon dioxide to silicon due to a larger solubility of $\mathrm{O}^{2-}$ ions which is important in the process. Adding other kinds of molten salts like $\mathrm{LiCl} \backslash \mathrm{KCL} \backslash \mathrm{CsCl}$ can lower the reaction temperature as well as decrease the reduction rate which is beneficial to minimize the silicon size.

\subsubsection{Silica}

The morphology and structure of final product of silicon electrolytic reduced from silica at high temperature can be completely different for different raw materials and reaction conditions. Typical morphologies include SiNWs, silicon nanoparticles, silicon nanotubes, silicon sheets, clusters of silicon elements, and so on.

Morphology of silicon dioxide may affect the reduced production [33]. In the very first report, Nohira et al. [18] used a quartz plate as $\mathrm{SiO}_{2}$ source and received the silicon layer with a thickness of 100-200 $\mu \mathrm{m}$, consisting of silicon columns of diameter 5-10 $\mu \mathrm{m}$. By further study using electron probe microanalysis (EPMA), the silicon purity of columns was found to be higher than $90 \mathrm{wt} \%$. In 2004, Jin et al. [22] used porous 
pelleted silica powder as starting material, while $\mathrm{W}-\mathrm{SiO}_{2}$ electrode, platinum wire and graphite rod were used as quasi-reference electrode and counter electrode respectively. By controlling the particle size of $\mathrm{SiO}_{2}$ powder, the electrolysis time was reduced to less than $4 \mathrm{~h}$, and the energy consumption was minimized. The resulting elemental silicon appeared as an irregular cluster structure.

Particle size of the silicon dioxide used could influence the final product. In 2011, Ergül et al. [32] performed electro-reduction of silica powders in different sizes which are sandwiched between two stainless steel sheets. By varying the silica size, it can be seen in Fig. $7(\mathrm{a}, \mathrm{b})$ that at $750{ }^{\circ} \mathrm{C}$, the reduction rate slightly increased with the decreasing particle size from sub- $64 \mu \mathrm{m}$ to sub-38 $\mu \mathrm{m}$. This is because that the smaller particle size yields condensed pellets which decreases the diffusion and the conduction paths.
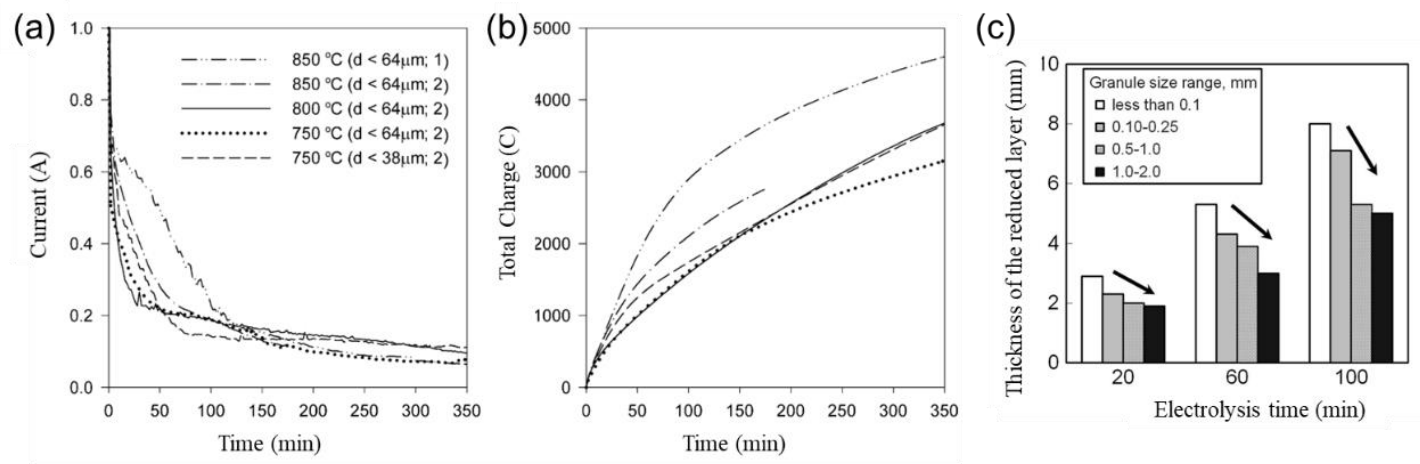

Fig. 7. (a) The relationship between electric current and time. (b) The relationship between the total charge and time in the electrolysis of pellets under different conditions. All these tests were made of $\mathrm{SiO}_{2}$ particles, without wire mesh, and were directly clamped between two stainless steel plates. Legends: d: particle size, 1: pure $\mathrm{CaCl}_{2}, 2$ : $\mathrm{CaCl}_{2}-\mathrm{NaCl}$ electrolyte. Reprinted from Ref. [32], with the permission of Elsevier. (c) 
Thickness of the reduced layers after electrolysis for 20, 60, and 100 min using $\mathrm{SiO}_{2}$ granules with different size ranges. Reprinted from Ref. [34], with the permission of Springer Nature.

Similar conclusions were drawn by Yang et al. in 2016 [34]. By investigating the effect of granule size of $\mathrm{SiO}_{2}$ granules on electrochemical reduction mechanism in molten salt, they found out that fine granules could be connected to higher reduction rate, as a result of the smaller contact potential drop between the bottom Si plate and the reduced Si. As shown in Fig. 7(c), the increased thickness and the faster growth of the reduced layer are attributed to the smaller granules. On the other hand, as the granule size decreases, diffusion of $\mathrm{O}^{2-}$ from the internal $\mathrm{SiO}_{2}$ becomes easier.

Except for silica, $\mathrm{CaSiO}_{3}$ can also be used as silicon source in electro-reduction [28]. Dong et al. produced silicon nanowires via direct electrochemical reduction of $\mathrm{CaSiO}_{3}$, at a low temperature of $650{ }^{\circ} \mathrm{C}$ by using low melting point ternary molten salts $\mathrm{CaCl}_{2}-\mathrm{MgCl}_{2}-\mathrm{NaCl}$. The selected raw material and molten salt could improve the transport of $\mathrm{O}^{2-}$ anions, and hence accelerate the reaction kinetics and enables the electrolysis at low temperatures.

\subsubsection{Additives}

Additives like metals can modify the morphology and structure of final silicon products in electrochemical reduction.

Yang et al. [24,25,35] electrochemical prepared silicon nanowires with the nanocopper powder (50 nm in diameter) mixed nano $\mathrm{SiO}_{2}$ as working electrode, at a constant potential of $1.20 \mathrm{~V}$, in molten salt $\mathrm{CaCl}_{2}$ at $900{ }^{\circ} \mathrm{C}$ for $4 \mathrm{~h}$. The SEM images of the 
obtained SiNWs are shown in Fig. 8(a). When nickel powder (50 $\mathrm{nm}$ in diameter) was added in the molten salt, SiNWs with a diameter of 200-300 nm decorated by nanoparticles can be obtained, which is shown in Fig. 8(b).

In 2016, the same group investigated the effect of nickel additive on silicon morphology [29]. They received large quantities of SiNWs by the electrochemical reduction of $\mathrm{Ni} / \mathrm{SiO}_{2}$ blocks $\left(\mathrm{SiO}_{2}: \mathrm{Ni}=20: 10\right.$, in molar ratio). Nickel additives repress the growth of irregular branches and promote longitudinal growth of SiNWs (Fig. $8(c, d))$. They also investigated the effect of time, temperature on the final morphology of SiNWs. 

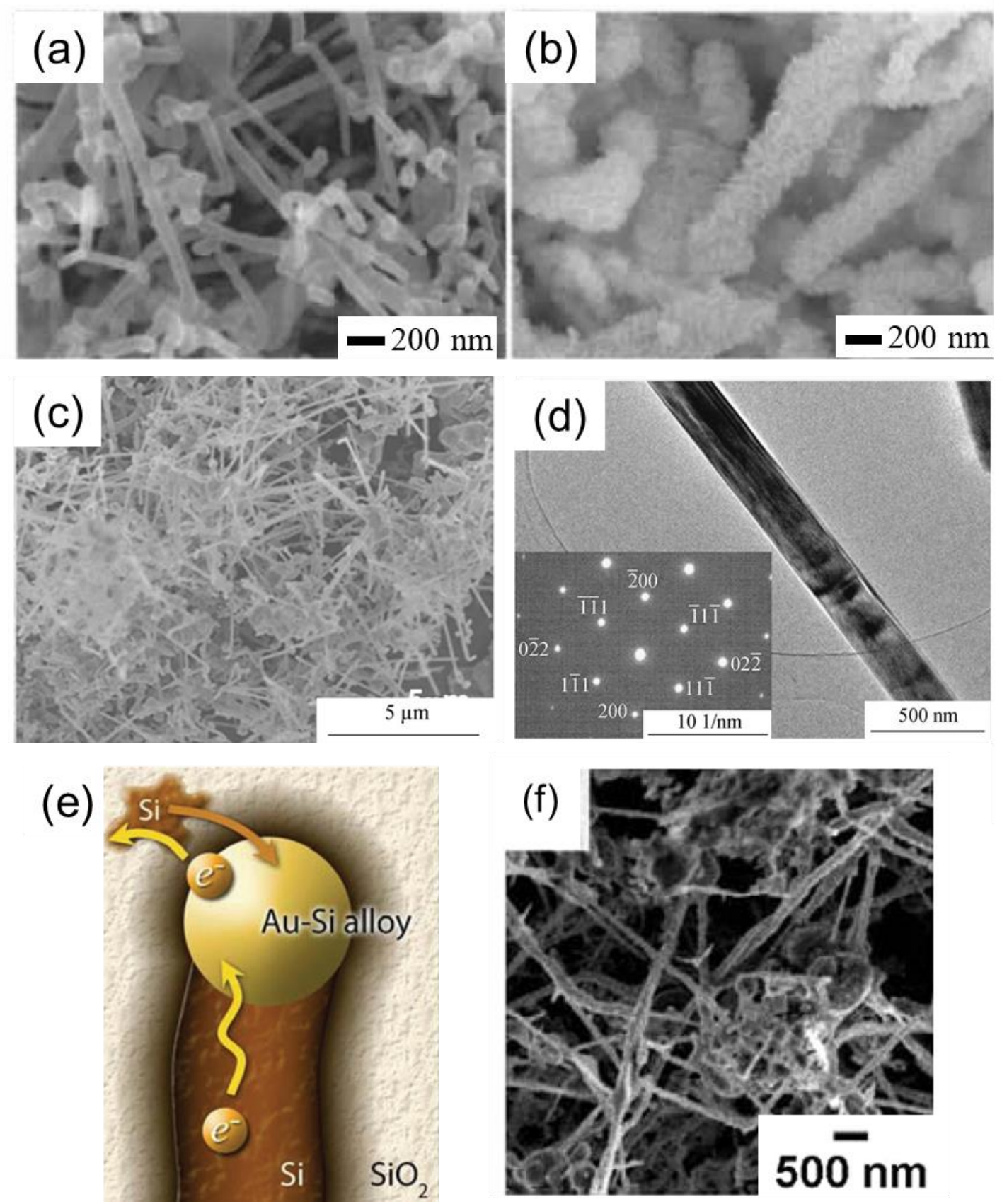

Fig. 8. SEM photograph of the sample produced with addition of (a) $\mathrm{Cu}$ powder in molten $\mathrm{CaCl}_{2}$ and (b) Ni powder in molten $\mathrm{CaCl}_{2}$. Reprinted from Ref.[35], with the permission of Chinese Journal of Inorganic Chemistry. (c) SEM images of reaction products obtained by electrochemical reduction of $\mathrm{Ni} / \mathrm{SiO}_{2}$ blocks $\left(\mathrm{SiO}_{2}\right.$ to $\mathrm{Ni}$ ratio $=$ 10) at $1.5 \mathrm{~V}$ for $5 \mathrm{~h}$ in molten $\mathrm{CaCl}_{2}$ at $1173 \mathrm{~K}$. (d) TEM image (inset being SAED pattern) of (c). Reprinted from Ref. [29], with the permission of Springer Nature. (e) 
The mechanism of SiNWs growth catalyzed by an Au NP. (f) Microstructure of SiNWs produced by the electrolysis with Au NPs. Reprinted from Ref. [26], with the permission of Electrochemical Society.

Nohira et al. [26] produced SiNWs using amorphous $\mathrm{SiO}_{2}$ pellets with a tetrapodlike microstructure as the starting material. The SiNWs showed irregular branching and ununiform diameters. However, elongated SiNWs were obtained during the electrolysis with the existence of $\mathrm{Au}$ nanoparticles. They suggested that Au nanoparticles could catalyze the longitudinal nanowire growth. At the high temperature, Au nanoparticles will alloy with the formed silicon into drop-like Au-Si alloy. The subsequent formation of silicon crystal would take place preferentially at the end of SiNW from the alloy liquid droplets (Fig. 8(e,f)). As the reduction proceeded, the silicon formation rate from electroreduction and from the oversaturated alloy may approach equilibrium and then the nanowires could grow continuously.

Except for metals, carbon is another useful additive in the raw material. In 2014, Nishihara et al. [36] prepared a carbon-coated silicon dioxide and finally got the composites of small Si nanocrystals $(<20 \mathrm{~nm})$ inside the shell-like carbon layer. The $\mathrm{Si}-\mathrm{C}$ nanocomposites were then used as the negatrode material in LIBs. We'll discuss this in section 4.

\subsection{Reaction parameters}

The reaction parameters including potential, time and devices also significantly affect the reaction. For example, potential controls the occurrence of the reaction, while reaction time determines the productivity. Devices may also influence the direction of 
reduction reaction. Therefore, effect of different reaction parameters on the obtained product will be discussed below.

\subsubsection{Electrolytic potential, time and temperature}

The potential nearly has the greatest influence on the electro-reduction. According to the existing knowledge, the optimal potential is between $0.7 \mathrm{~V}$ and $1.25 \mathrm{~V}$.

As mentioned by Nohira et al. [37], when the electrode potential of conductive material is greater than that of the reduction potential of $\mathrm{SiO}_{2}$, it is considered that electric deoxidation occurs at the three-phase interface between $\mathrm{SiO}_{2}$, conductive material and molten salt. The diffusion rate of oxygen ion affects the reaction rate in the early stage of the reaction.

The effect of electrode potential and time on the reduction was studied by Yasuda et al. [38]. They performed potentiostatic electrolysis in the range of $0.35-1.3 \mathrm{~V}$. Fig. 9(a) shows the current-time curves, and we can analyze the influence of potential and time on cathodic current values, which are in accordance with the reduction rates. No reduction occurred at $1.30 \mathrm{~V}$ and $\mathrm{Si}-\mathrm{Ca}$ alloy formed at $0.35 \mathrm{~V}$. At all other potentials, the cathodic current increases with time, corresponding to the reaction interface growth. For reduction at $0.35 \mathrm{~V}$ and $0.70 \mathrm{~V}$, the current values increase first and then decrease, demonstrating that the rate of the whole reaction decreases obviously after the surface is completely reduced. Meanwhile, the current values are higher with the more negative potential, because the reduction rate will considerably increase at more negative potentials. 

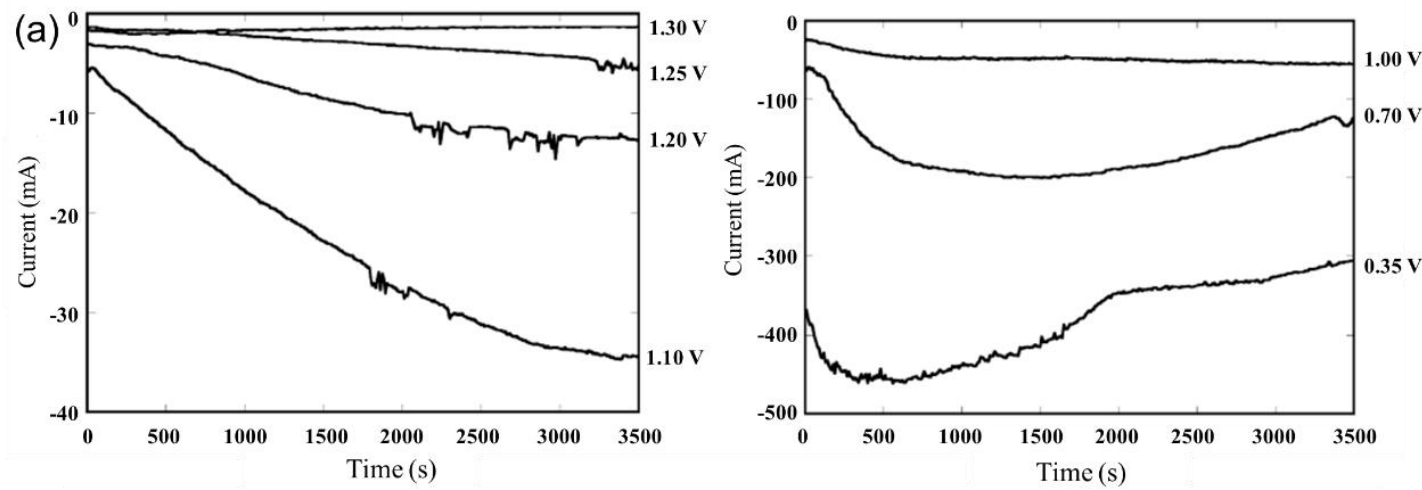

(b)
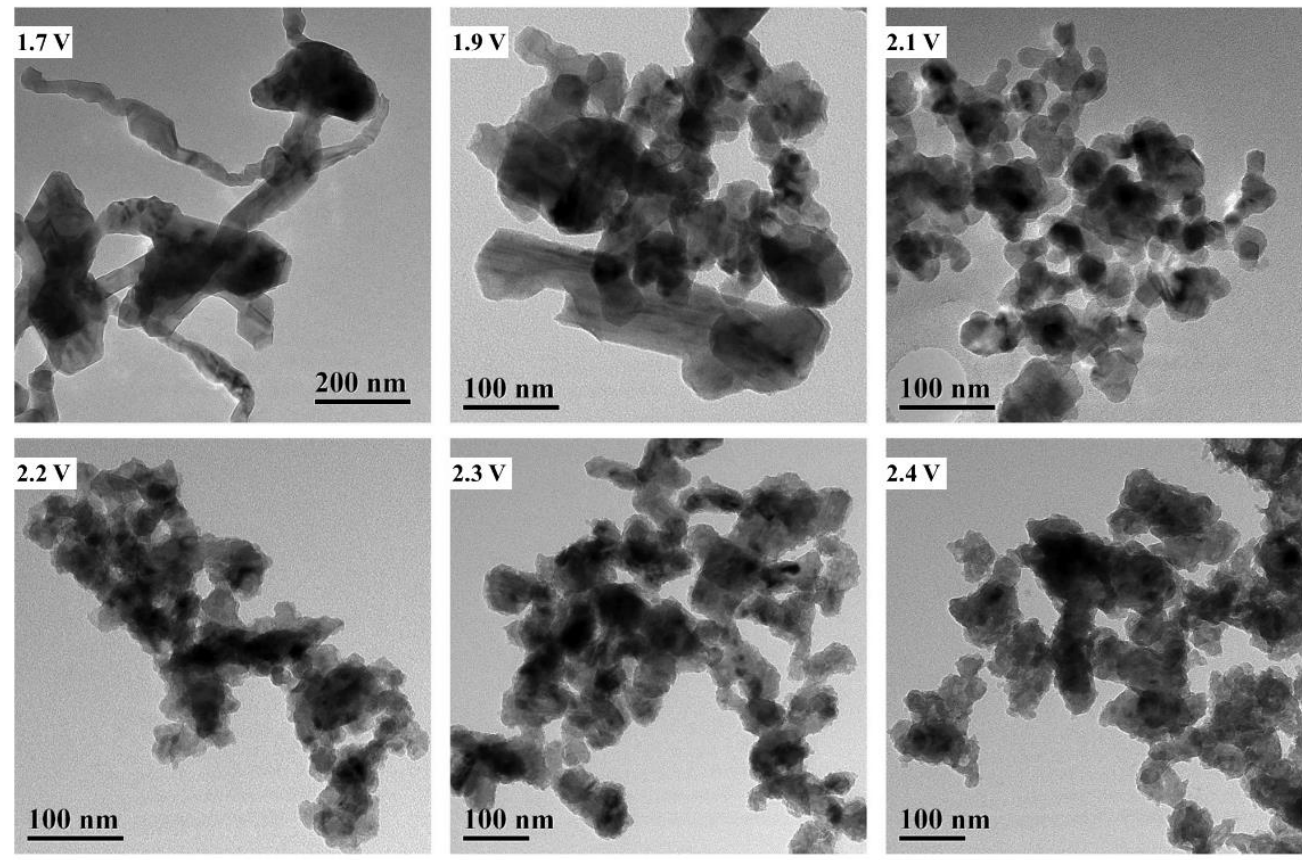

Fig. 9. (a) Current-time curves during the potentiostatic electrolysis of $\mathrm{SiO}_{2}$ contacting electrodes at different potentials in molten $\mathrm{CaCl}_{2}$ at $1123 \mathrm{~K}$. Reprinted from Ref. [38], with the permission of Elsevier. (b) TEM images of samples prepared at different cell voltages. Reprinted from Ref. [30], with the permission of Elsevier.

Similarly, in 2006, Xiao et al. [21] used twisted molybdenum wire around a quartz plate about two centimeters in diameter for electrolysis. During the process of electrolysis, the reduction rate increased with the increase of overpotential, and the reduction is determined by the diffusion of $\mathrm{O}^{2-}$ and ohmic polarization at a certain potential. The possible precipitation of $\mathrm{CaO}$ will retard the process when applying a 
very large overpotential. At a given potential, there is a positive relationship between the reduction depth and the electrolysis time. And in 2012, Xiao et al. [39] found that the deposition potential of calcium silicate is $0.75 \mathrm{~V}$, which is higher than that of silicon calcium alloy. This is because that there is a $2 \%$ mole fraction of calcium oxide in the molten calcium chloride salt. With the electrolysis proceeding, the generated oxygen ions react with silica to form calcium silicate. Finally, the mixture of SiNWs and silicon nanoparticles was obtained.

The morphology and composition of silicon productions can be modified by controlling reduction potential. In 2013, Zhao et al. [30] conducted electro-reduction reaction at potential of $1.7-2.1 \mathrm{~V}$ and obtained nano-sized silicon. As can be seen in Fig. 9(b), all samples at different potentials exhibit the cluster morphology consisting of nano particles with diameters of 20-100 nm. Samples obtained at $1.7 \mathrm{~V}$ exhibit loose and long-branch like morphology, and the branches get shorter gradually as the voltage increase to $2.1 \mathrm{~V}$. When the voltage increases above $2.2 \mathrm{~V}$, the silicon nanoparticles become less dense and smooth, indicating some porous structure as a result of amorphous $\mathrm{SiO}_{2}$ around the surface. The morphology becomes more unregular at 2.4 $\mathrm{V}$, which is in accordance with the deduced effect from Ca-Si compounds.

$\mathrm{NaCl}-\mathrm{CaCl}_{2}$ system molten salt are always used to conduct electrochemical reduction at different temperatures. In Fig. 7(a,b), Ergül et al. [32] investigated the current at different temperature. Yang et al.[35] obtained different morphologies of nano silicon by adjusting the reduction temperature. Nano-silicon with porous mesh pattern was received at $600{ }^{\circ} \mathrm{C}$ for $4 \mathrm{~h}$. When increasing the temperature to $700{ }^{\circ} \mathrm{C}$, a few 
nanowires were found, the majority of product were ununiform nanoparticles with a diameter of about $40-50 \mathrm{~nm}$.

\subsubsection{Contacting electrode}

Contacting type and contacting meatal materials also influence on the electroreduction. Yasuda et al. [40] used a new type of contact electrode, which was a carbonfree anode to prevent metal contamination. The silicon dioxide was sandwiched by two parts of solar-grade silicon and then two silicon plates were used as contacting electrode. This kind of electrode has high purity and high temperature resistance. A mixture of columnar silicon and $\mathrm{SiO}_{2}$ can be obtained after electrolysis, and the final product was of high purity.

Ergül et al. [41] put the porous $\mathrm{SiO}_{2}$ pellet sandwiched between two metal plates. Stainless steel was used as cathode contacting materials instead of nickel in other former work. After reduction, $\mathrm{Fe}-\mathrm{Si}$ intermetallic and $\mathrm{CaCO}_{3}$ were observed, but the amount was less than nickel-silicon intermetallic compounds in reaction with nickel as contacting metal, leading to more silicon reduction.

\section{Application of nano-silicon from molten-salt electrolysis in new energy sources}

As the basic material of integrated circuit and solar cells, silicon is in long-term large market demand due to the rapid development of information and photovoltaic industry. At present, the preparing methods of silicon include Czochralski process, casting, float-zone melting, chemical vapor deposition, and so on. Most of these methods are high energy consumption, high cost and environmentally unfriendly. 
Silicon prepared by electrochemical reduction in molten salt has a prospective application in new energy field due to lower cost, less carbon emission and a briefer device. The obtained silicon can be applied in energy devices such as LIBs and solar cells with several advantages. In addition to those mentioned above, the FFC Cambridge Process can produce nanostructures with controllable morphologies and structures in an easy and convenient way for LIBs, and it's much more energy-efficient compared to the magnesiothermic reduction process and the CVD method. It can also provide a new idea for achieving advanced light trapping surface structure to enhance anti-reflection of the front surface thus improving performance when applied to fabricate silicon solar cells.

\subsection{Application as the negatrode material for LIBS}

Due to the high specific charge capacity [42], the low discharge potential, the high abundance and good environmental compatibility, silicon material has become a promising negatrode material as in LIBs. However, there are still several problems need to be solved in practical application. The large volume change (more than $300 \%)[43,44]$ during the charge-discharge process, the relatively low diffusion rate of lithium ion and electron, and the repeatedly formed solid electrolyte film may lead to poor cycle performance, low initial coulomb efficiency and poor rate performance [45]. To solve these problems, the present research mainly focusses on the design of silicon nanostructures and modification of silicon anode materials by composite with other materials. The usual methods to prepare nano silicon material such as magnesiothermic reduction, etching or CVD are mostly expensive, complicated and difficult to precisely 
control. The electro-reduction method could provide nano-sized and morphologycontrollable silicon materials, which could therefore exhibit excellent properties.

A new silicon-carbon core-shell structure was proposed by Nishihara et al. in 2014 [36], exhibiting good cycling performance as the negatrode of LIBs. Firstly, a thin carbon layer (several nanometers thick) was coated on the surface of $\mathrm{SiO}_{2}$ nanoparticles with diameter less than $50 \mathrm{~nm}$ by pulsed chemical vapor deposition (CVD) (Fig. 10a). Then, $\mathrm{SiO}_{2} / \mathrm{C}$ nanocomposites were electrochemically reduced in molten $\mathrm{CaCl}_{2}$ (Fig. 10b). $\mathrm{SiO}_{2}$ nanoparticles with appropriate thick carbon coating were successfully reduced into Si nanocrystals $(<20 \mathrm{~nm})$. Because of the volume difference between $\mathrm{SiO}_{2}$ and corresponding $\mathrm{Si}$, and some unreduced $\mathrm{SiO}_{2}$ can be removed by $\mathrm{HF}$ washing, nanopores were formed around Si nanoparticles. Therefore, a unique silicon-carbon core shell structure was obtained (Fig. 10c).

The TEM image of the reduced $\mathrm{SiO}_{2} / \mathrm{C}$ (carbon-loading amount $12 \mathrm{wt} \%$, sign as SNP(12)R-HF) is shown in Fig. 10(d). Compared to the similar sample with less carbon loading (6 wt $\%$, sign as $\mathrm{SNP}(6) \mathrm{R}-\mathrm{HF}), \mathrm{SNP}(12) \mathrm{R}-\mathrm{HF}$ has an integrated carbon layer which support the silicon nano crystals and nanopore inside it. As a result, this core shell nano structure could provide better cycle performance. The specific capacity of SNP(12)R-HF is relatively lower at the beginning than that of SNP(6)R-HF, due to less ratio of silicon, but performs a slow decay in subsequent cycles. The carbon coating can act as supporting structure to regulate silicon crystal growth during the reduction process and provide space for volume expansion of silicon. On the other hand, as a conductive material, carbon layer can improve the carrier diffusion property in the 
whole composites. Although the electrochemical performances are not very satisfying, this work on Si-C core-shell structure proves electro-reduction in molten salt to be a new and practicable method of preparing Si-C composites as LIBs electrodes.

Recently, Weng et al. [46] proposed a pyrolysis-cum-electrolysis process to prepare a Si@C@Si hybrids by electrolysis of $\mathrm{SiO}_{2} @$ polydopamine in molten NaCl$\mathrm{CaCl}_{2}$ at $800{ }^{\circ} \mathrm{C}$, see Fig. $10(\mathrm{e})$. The polydopamine (PDA) coating can accelerate electroreduction of $\mathrm{SiO}_{2}$ by acting as a depolarizer and retarded generation of inconvenient $\mathrm{SiC}$, leading to a composition of outmost silicon thin layers due to electrodeposition, sandwiched N-doped carbon hollow spheres derived from pyrolysis of PDA, and encapsulated silicon nanoparticles. By tailoring the electrolysis conditions, an excellent electrochemical performance can be obtained for hybrids electrolyzed at 2.6 V for $2 \mathrm{~h}$. The reversible specific capacity of $904 \mathrm{mAh} \mathrm{g}^{-1}$ was achieved after 100 charge/discharge cycles at $500 \mathrm{~mA} \mathrm{~g}^{-1}$. The rate performance was also outstanding. At the high current laod of $1000 \mathrm{mAh} \mathrm{g}^{-1}$, the capacity still stayed around the high value of $\sim 887 \mathrm{mAh} \mathrm{g}^{-1}$, after 100 cycles as shown in Fig. 10(f).
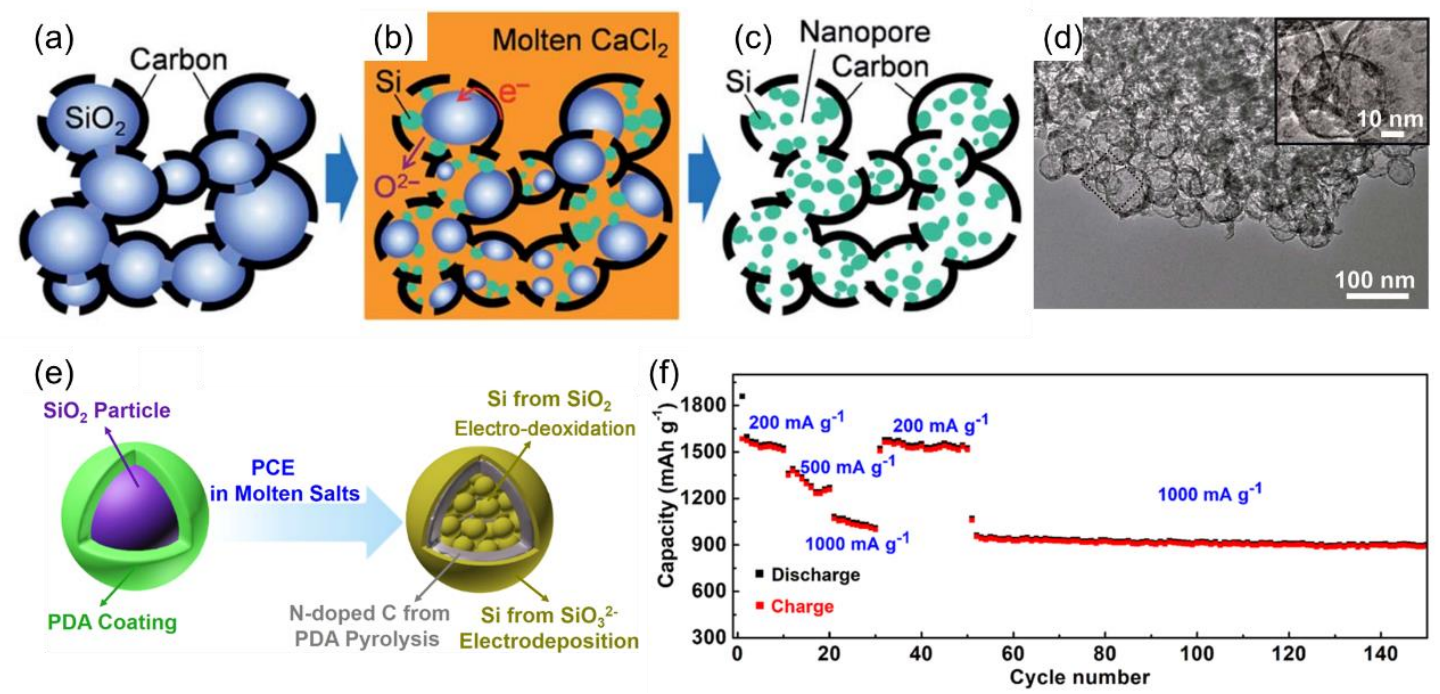
Fig. 10. A scheme of electrochemical conversion of $\mathrm{SiO}_{2}$ nanoparticles into silicon nanocrystals. (a) $\mathrm{SiO}_{2}$ nanoparticles covered with a carbon nanolayer. (b) Electrochemical reduction of the $\mathrm{SiO}_{2}$ nanoparticles into silicon nanocrystals in molten $\mathrm{CaCl}_{2}$. (c) Silicon nanocrystals, together with nanopores, encapsulated with the original carbon layer. (d) TEM images of SNP/C(12)R-HF. An enlarged image of the highlighted region by a dotted line is shown as the inset. Reprinted from Ref. [36], with the permission of Royal Society of Chemistry. (e) Schematic illustration of pyrolysiscum-electrolysis preparation of Si@C@Si hybrids. (f) The rate performance of the Si@C@Si hybrids. Reprinted from Ref. [46], with the permission of American Chemical Society.

Compared with silicon particles, silicon nanowires and silicon nanotubes have no obvious transverse volume effectercalation of lithium [43]. They will not lose electrical contact due to pulverization as silicon nanoparticles do, thus leading to better cycle stability. They can also achieve high specific capacity due to the fast and thorough lithium deintercalation with small diameter. Silicon nanowires are important candidates in LIBs, as a result of their better carries transportation property and larger tolerance to volume expansion. In 2018, Weng et al. [47] prepared silicon nanowires by electrolysis in molten salt both on carbon cloth to form a Si-C composites and as silicon powders.

Fig. 11(a) shows the schematic of the carbon cloth cathode before and after deposition of SiNWs. SEM images can be found in Fig. 11(b,c,d) for SiNWs on carbon cloth and as powders respectively. The diameter of the achieved SiNWs is about 20-30 $\mathrm{nm}$ in diameter and the surface oxide layer is about $1 \mathrm{~nm}$ thick, much smaller than those 
of silicon powders (100-200 $\mathrm{nm}$ in diameter, $12 \mathrm{~nm}$ thickness of oxide layer). Meanwhile, SiNWs on carbon cloth can work as a binder-free electrode. Benefiting from the specific structure and the synergistic effect with carbon, the electrodeposited SiNWs on carbon cloth present excellent electrochemical performances. The nanowire morphology and ultra-thin oxide layer can stabilize the whole material structure and alleviate the volume change during charge/discharge process, leading to long cycle life. Smaller size can provide shorter diffusion path of electron and Li ion, resulting good rate performance. As shown in Fig. 11(e), the initial Coulombic efficiency is high and the reversible capacity can reach $711 \mathrm{mAh} \mathrm{g}^{-1}$ after 200 galvanostatic charge/discharge cycles at $1000 \mathrm{~mA} \mathrm{~g}^{-1}$ as well, eight times higher than that of the electrolyzed silicon powder. And for the electrodeposited silicon on carbon cloth, the capacities of 1580 , 1316, and $1218 \mathrm{mAh} \mathrm{g}^{-1}$ can be delivered at 200, 500, and $1000 \mathrm{~mA} \mathrm{~g}^{-1}$, respectively, much higher than capacities of the directed electrodeposited silicon powder (Fig. 11f). These results show possibility of application and even scale production of Si-C nano composites by electrochemical reduction in molten salt. 


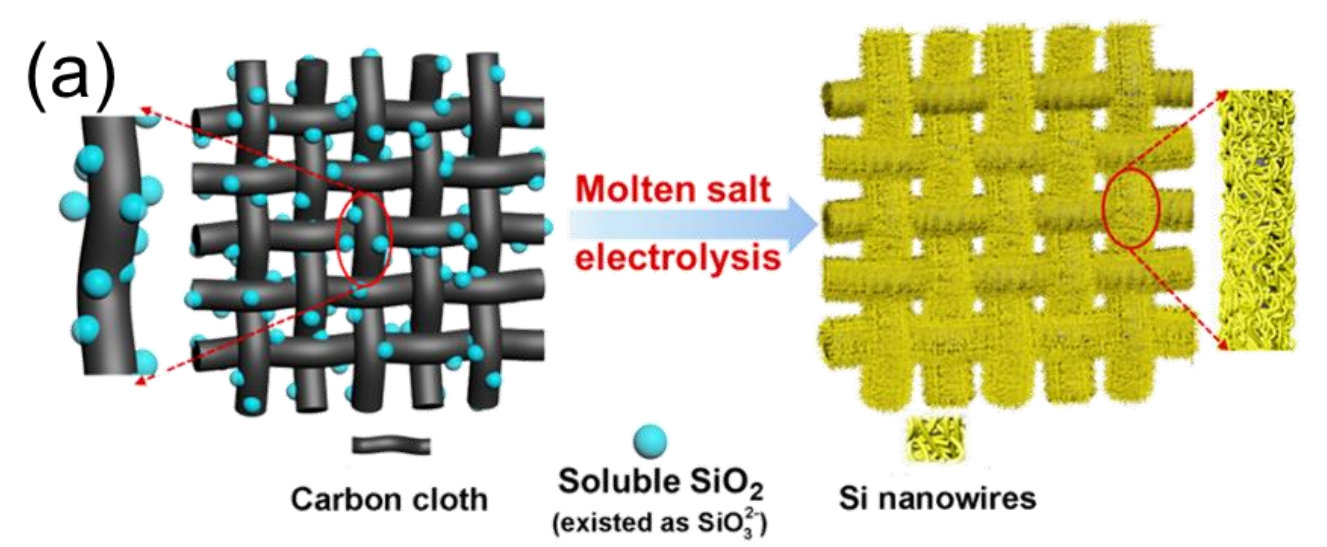

Carbon cloth before electrolysis

Binder-free carbon cloth with deposited Si nanowires
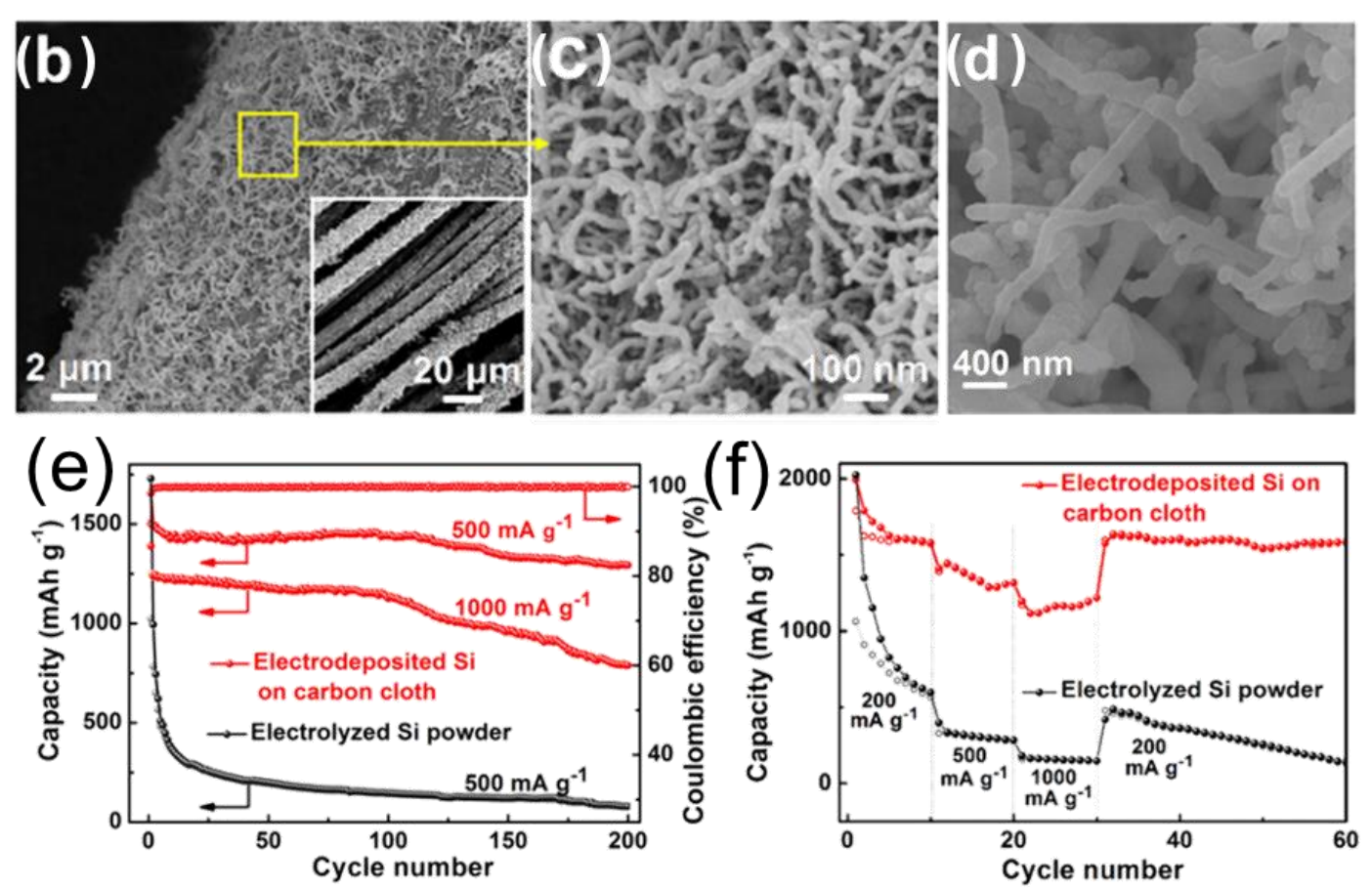

Fig. 11. (a) Illustration of carbon cloth cathode before and after deposition of SiNWs.

SEM images of electrodeposited silicon on carbon cloth (b, c) and electrolytic silicon powder (d). All of the electrolysis processes are conducted at $0.3 \mathrm{~V}$ vs. $\mathrm{Ca} / \mathrm{Ca}^{2+}$; Electrolysis time is $1.5 \mathrm{~h}$ for soluble $\mathrm{SiO}_{2}$ and $12 \mathrm{~h}$ for solid $\mathrm{SiO}_{2}$ pellets. (e) Cycling performance of the electrodeposited silicon on carbon cloth and the electrolyzed $\mathrm{Si}$ powder as well as the Coulombic efficiency of electrodeposited Si on carbon cloth at $500 \mathrm{mAh} \mathrm{g}^{-1}$. (f) Rate capabilities of the electrodeposited silicon on carbon cloth and 
the electrolyzed silicon powder. Reprinted from Ref. [47], with the permission of American Chemical Society.

Silicon nanotube with unique hollow structure may have excellent electrochemical properties as SiNWs. The larger free surface inside and outside the silicon nanotube can well adapt to the radial volume expansion and form a more stable SEI during charging and discharging, which makes the material may present a higher Coulomb efficiency than that of SiNWs. In 2016, Xiao et al. [48] synthesized the crystalline silicon/germanium $(\mathrm{Si} / \mathrm{Ge})$ alloy nanotubes for the first time by tuning the overpotential. The schematic of the synthesis is shown in Fig. 12(a). The morphology and structure are characterized by SEM and TEM which are shown in Fig. 12(b,c). Fig. 12(c) shows that the electrolytic SiGe product exhibits a typical nanotube morphology with open ends. The diameter and the tube wall thickness are around $20 \mathrm{~nm}$ and several nanometers, respectively. The alloy nanotubes show better lithium storage performance as negatrode materials for LIBs due to their composition and structure advantages compared to solid Si and Ge nanowires (Fig. 12(e,f)). The prepared SiGe nanotubes show good cycle performance, with a reversible capacity of $590 \mathrm{mAh} \mathrm{g} \mathrm{g}^{-1}$ after 100 cycles, better than those of SiNWs and GeNWs. The sample also presents a reversible lithium storage capacity of larger than $650 \mathrm{mAh} \mathrm{g}^{-1}$ at $1 \mathrm{~A} \mathrm{~g}^{-1}$. 
(a)

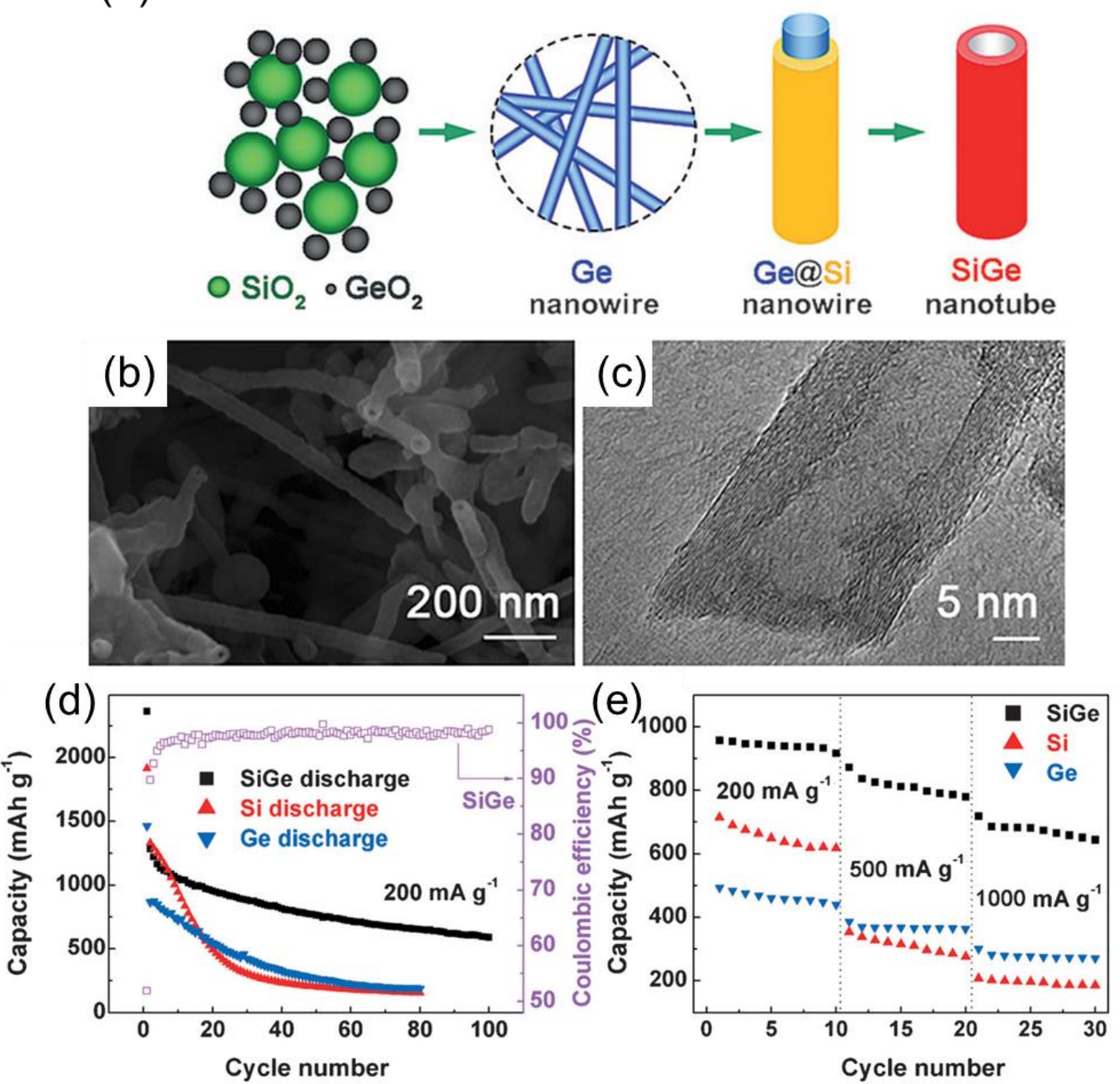

Fig. 12. (a) Schematic illustration of synthesis of SiGe nanotubes from electroreduction of mixture of solid $\mathrm{SiO}_{2}$ and $\mathrm{GeO}_{2}$ particles in molten chlorides. This one-pot electrolytic synthesis includes the formation of Ge nanowires, Ge@Si core-shell structures, and the subsequent solid diffusion process for the formation of SiGe nanotubes. SEM (b) and TEM image (c) of SiGe nanotubes obtained upon electrolysis at $2.1 \mathrm{~V}$ for $12 \mathrm{~h}$. (d) Cycling performance of SiGe nanotubes, SiNWs, and Ge nanowires and the corresponding Coulombic efficiency of SiGe products at $200 \mathrm{~mA} \mathrm{~g}^{-}$ 1. (e) Rate capabilities of SiGe nanotubes, SiNWs and Ge nanowires after cyclic 
voltammetry scans for 5 cycles at $0.2 \mathrm{mV} \mathrm{s}^{-1}$. Reprinted from Ref. [48], with the permission of John Wiley and Sons.

Except for the $\mathrm{Si} / \mathrm{C}$ composites, $\mathrm{Si} /$ Metal composites have also been reported to be prepared by electro-reduction in molten salt. Zhou et al. [49] obtained $\mathrm{Cu}_{9} \mathrm{Si} / \mathrm{Si}$ composite nanowires by utilizing $\mathrm{SiO}_{2}$ and $\mathrm{Cu} / \mathrm{SiO}_{2}$ mixture as the raw materials. $\mathrm{Cu}$ ingredient can catalyze the growth of silicon nuclei to generate straight wires and the final composites exhibits the better cycling stability and rate performance. By utilizing $\mathrm{SiO}_{2}$ and $\mathrm{TiO}_{2}$ mixture as the different raw materials, they [50] prepared $\mathrm{Si} / \mathrm{Ti}$ composites, which has the enhanced reversible specific capacity and good cycling stability with a high retention of $92.2 \%$ after 50 cycles.

As a result, the research on application of electrolytic silicon in LIBs is still not comprehensive, but the existing work provide us a new route in large scale production of silicon-based LIBs negatrode materials.

\subsection{Application in solar cell}

Silicon based solar cells, including monocrystalline, multicrystalline and amorphous silicon solar cells, have been dominating the market for a long time. Reducing the cost and increase optical-to-electrical conversion efficiency are two important factors for further development of Si photovoltaics (PV). Generally, the electrolysis in molten salt method could be utilized in reduction, purification of silicon material, anti-reflection by producing black silicon in silicon PV. Meanwhile, highpurity photo-responsive nanostructured silicon [51] from the electro-reduction is promising in photovoltaic and photocatalytic area. 


\subsubsection{Reduction of metallurgical grade silicon to solar grade silicon}

In the whole cost of silicon PV, expenses of silicon material preparation and crystal growth take a large proportion. The current PV-silicon producing technique is the carbothermic reduction of $\mathrm{SiO}_{2}$ followed by a modified Siemens process. This technique suffers serious carbon releasing, high energy consumption and thermal releasing. As a fast, low-cost and low energy-consuming method, molten-salt electrolysis is promising to prepare silicon from $\mathrm{SiO}_{2}$ by electroreduction or to purify silicon from the metallic silicon.

Since 2011, several researchers [30,37,52-54] achieved solar grade silicon with high purity by electro-reduction using metallurgical grade silicon or silicon dioxide as raw materials.

Zou et al. [52] used high purity metallurgical grade silicon as raw material, $\mathrm{KCl}$ $\mathrm{NaF}$ as molten salt, metallurgical grade silicon as anode and $\mathrm{Ni}$ crucible as cathode for collecting silicon powder. The electrolysis was proceeded at $2.0 \mathrm{~V}$ and $800{ }^{\circ} \mathrm{C}$ for $14 \mathrm{~h}$. During the electrolysis, the metallurgical grade silicon was dissolved and then deposited on the cathode through mixture molten salt electrolyte. The purity of the received silicon was $99.99 \%$, and most of the electroactive impurities including boron, phosphorus and aluminum were eliminated. Impurity level was nearly reaching to solar cell grade. The content of impurities can be seen in Table 2. The metallic impurities content, especially the transition metallic impurities which can be detrimental to the solar cell properties, was also reduced by a large margin, leading to less recombination loss in the subsequent devices. 
Table 2. Content of impurities of raw material and product.

\begin{tabular}{ccccccccc}
\hline & $\mathrm{7e}$ & $\mathrm{Al}$ & $\mathrm{Ti}$ & $\mathrm{Mn}$ & $\mathrm{B}$ & $\mathrm{P}$ & $\mathrm{Cu}$ & $\mathrm{Ca}$ \\
\cline { 2 - 8 } & $>2800.0$ & 1300 & 157.0 & 180.4 & 56.0 & 108.0 & 18.6 & 263.1 \\
\hline $\begin{array}{c}\text { Metallurgical grade } \\
\text { silicon } \\
\begin{array}{c}\text { Electrorefined } \\
\text { silicon }\end{array}\end{array}$ & $<10.0$ & 7.0 & 1.6 & 4.8 & 11.0 & 8.0 & 2.7 & 4.3 \\
\hline
\end{tabular}

In 2013, Yasuda et al. [37] performed direct electro-reduction of solid $\mathrm{SiO}_{2}$ in molten $\mathrm{CaCl}_{2}$ at $1123 \mathrm{~K}$ to produce solar-grade silicon. As discussed in the above section, a novel electrode contacting method was used to reduce contacting contamination. The concentrations of metal impurities in the produced silicon were significantly reduced. The concentrations of most of the impurity elements were below their respective target concentrations. By filling the gap between the conductive material and the $\mathrm{SiO}_{2}$ tube with fine $\mathrm{SiO}_{2}$ powder, the reduction speed was improved. Electrical contact was maintained by the connections between silicon tubes produced during reduction process.

Zhao et al. [30] also used the FFC-Cambridge Process to prepare silicon from $\mathrm{SiO}_{2}$ to obtain nanostructured and highly pure silicon for solar cells. The quartz glass plate was chosen as the starting material, and by verifying reaction factors as discussed in section 3, controllable nano cluster-like silicon in $20-100 \mathrm{~nm}$ size with purity of $99.95 \%$ had been prepared by complete conversion.

\subsubsection{Reflection reduction of solar cell by electrolysis in molten salt}

Among all the strategies to improve efficiency, reducing the light loss by surface treatment is important and basic which can be applied in cell manufacturing. Advanced light trapping surface structure like texture and coatings can enhance anti-reflection of 
the front surface $[1,55]$. At present, to reduce the reflection of the wafer to achieve a higher light absorption probability, the common surface texturization is utilized by chemical etching. For single crystalline silicon, alkaline solution and acid solution could etch the monocrystalline and multicrystalline silicon, leaving the light-trapping pyramid-like or massif-like surface. Electrolysis in molten salt reaction could provide a new idea to realize anti-reflection by producing the black silicon.

Work on producing black silicon by electrolysis in molten salt focused on the novelty of the process and the morphology of the textured surface structures formed was started in 2010. Juzeliunas et al. [56] used silicon with thermal oxide layer as raw material and calcium chloride as molten salt in electrolysis. The reaction lasted for 20 h. They received a thin layer of silicon surface texturing on nano-micro-scale with a single spheroid with submicron structure. Oxygen ions produced by the electrolysis of silica affect the local current and thus affect the speed of the reaction. The final product is brown with low reflectivity which may be attributed to the precipitation of calcium oxide on the surface. In 2012, Juzeliunas et al. [57] electro-deoxidized the $2 \mu \mathrm{m}$ thick silicon dioxide layer on p-type silicon at $850^{\circ} \mathrm{C}$ in molten calcium chloride. Fig. 13(a) shows the SEM image after electro-deoxidation at $E=-1.0 \mathrm{~V}$, and $t=20 \mathrm{~min}$. A globular network with micrometer sized pores and nano-fiber structure on the top was observed. The photo of propagation of the reduced area (black) over the wafer surface can be seen in Fig. 13(b). The surface reflection is reduced obviously after electrolysis for different time (Fig. 13c). The surface can absorb light effectively with a reflectivity of up to $8 \%$, suitable for silicon PV application 
In 2015, Coxon et al. [58] also proposed a light capture scheme. Light loss is minimized by scattering and reflection, thus increases the light absorption and the number of carriers generated. The photograph of the prepared black silicon wafer can be found in Fig. 13(d).

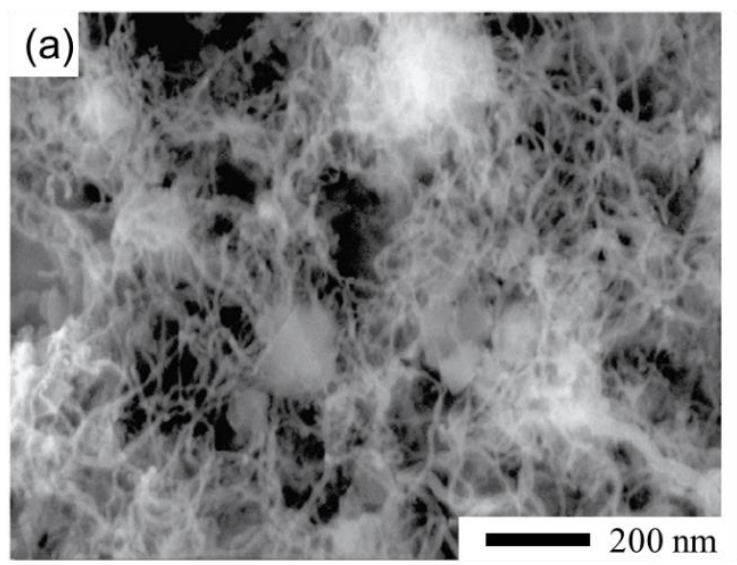

(b)
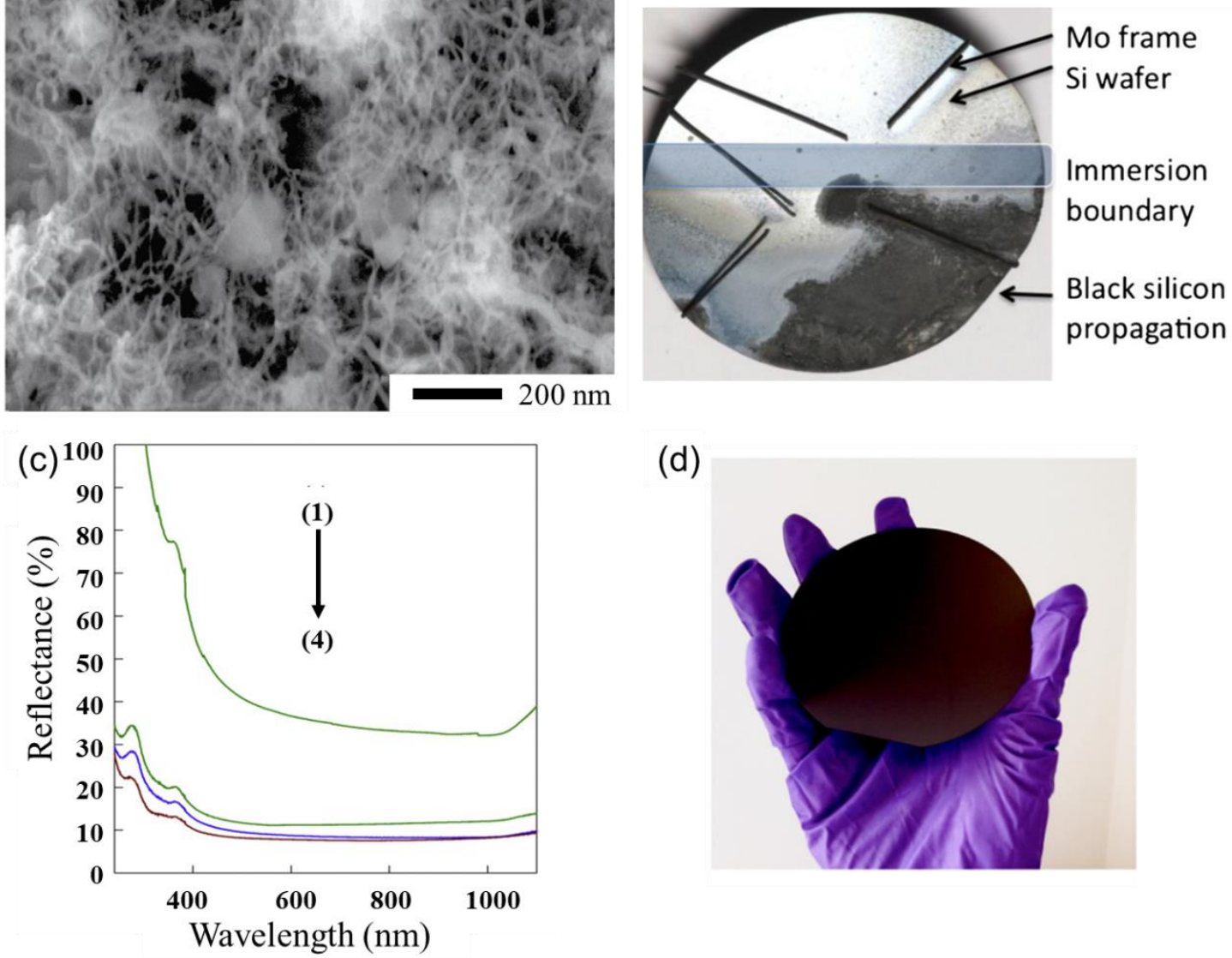

(d)

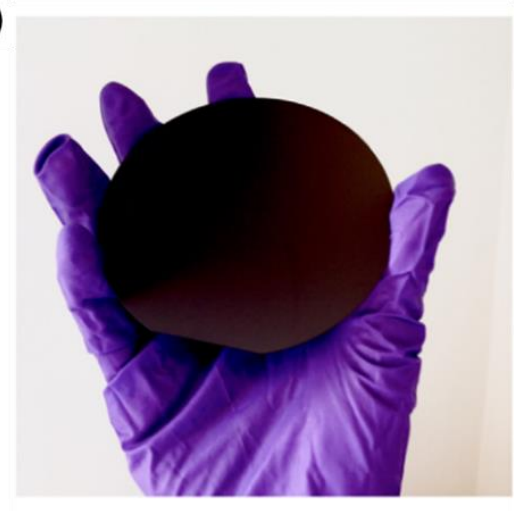

Fig. 13. (a) $\mathrm{SEM}$ images of $2 \mu \mathrm{m} \mathrm{SiO}_{2}$ precursor after electro-deoxidation at $E=-1.0$ $\mathrm{V}$, and $t=20 \mathrm{~min}$. (b) Propagation of the reduced area (black) over the wafer surface. (c) Surface reflectance spectra of bare silicon, electro-deoxidized surfaces for $1 \mathrm{~h}, 17$ min, and $3 \mathrm{~min}$ (from top to bottom). Reprinted from Ref. [57], with the permission of Elsevier. (d) Photograph of the electrolytic reduced black silicon wafers. Reprinted from Ref. [58], with the permission of Elsevier. 
The electro-reduction method to prepare anti-reflection layer of silicon provides a new and environmentally friendly idea to silicon PV. However, there are still some problems in real application. Reaction in such high temperature for such a long time may induce contaminations into silicon material, which are detrimental to the final cell performances. Besides, it is not easy to realize in large-scale production.

\section{Conclusions and perspectives}

Due to the depletion of fossil energy and the impact of carbon dioxide emissions on the global climate, novel silicon preparation technology with low-energy consumption, low-cost, low-pollution are in urgent need of development. The process of preparing silicon by direct electrochemical reduction of silica in molten salt is more advantageous than the traditional process: lower pollution, simpler process, easier to obtain raw materials and it can directly prepare silicon materials with higher purity. It can also prepare silicon nanomaterials with different morphologies and structures by controlling reaction conditions in large-scale. Thus, it may develop into a new important preparation method of silicon nanomaterials. However, there are still several fundamental problems unsolved towards the industrialization of this method. (1) The electrolysis deposition rate of silicon is slow due to its poor conductivity; thus, it will take a lot of time to electrolysis in industrial production process due to the large amount.

(2) The produced Si shows higher purity than that produced by the carbothermal reduction method, but it has not yet reached the purity requirement of solar grade silicon. (3) For semiconductor silicon, there will be severe ohmic polarization in large-scale 
production, which will affect the degree of reduction completion. The surface layer will be contaminated by calcium alloy with Si. (4) Energy efficiency. Not all current is used to produce elemental silicon, and there is no obvious advantage in efficiency. It is conceivable to try to overcome these problems by taking some strategies such as tailoring the reaction conditions. The energy efficiency can be reduced further by exploring the moderate electrolysis condition, for example the molten salt with lower electronic conductivity and reaction temperature. High-purity raw material and a novel reactor built from high-purity quartz or graphite with high-purity silicon nitride coating can be utilized to improve the purity of the final electrolysis products. Meanwhile, the electrode material can be replaced by silicon crystal to minimize metallic contamination from the metal current collector. Since the electrolysis reduction is quite efficient to remove some electrical impurities like B and $\mathrm{P}$, it can be combined with for example the upgraded-metallurgical method for further purification.

On account of the poor conductivity of silicon or silica, improving the conductivity of raw material by combining with some high-conductivity material like carbon or metal. The reduction efficiency can be improved and a $\mathrm{Si} / \mathrm{C}$ or $\mathrm{Si} /$ metal composites can be achieved in the same step, which is beneficial for use as the negatrode material in LIBs. On the other hand, in molten salt electrolysis, a liquid metal electrode may be utilized instead of the normal cathode, and it will lead to a higher contacting area between the electrode and silicon or silica, and a higher reduction rate, ensuring a steady reaction under the high electric current density. In this way, the process is expected to replace the current high energy consumption and high pollution silicon production 
process and directly apply to silicon-based solar cells and LIBs anode materials as a promising material preparation method for energy materials.

\section{Acknowledgments}

This work was supported by the National Natural Science Foundation of China (No. 51602234), Ningbo Municipal Government (3315 Plan and 2014A35001-1) and UK

Engineering and Physical Science Research Council (EP/J000582/1, GR/R68078).

\section{Reference}

[1] A. Goodrich, P. Hacke, Q. Wang, B. Sopori, R. Margolis, T.L. James, M. Woodhouse, Sol. Energy Mater. Sol. Cells, 114 (2013) 110-135.

[2] J. Nijs, J. Szlufcik, J. Poortmans, S. Sivoththaman, R. Mertens, Sol. Energy Mater. Sol. Cells, 65 (2001) 249-259.

[3] M.Y. Ge, J.P. Rong, X. Fang, C.W. Zhou, Nano Lett., 12 (2012) 2318-2323.

[4] M. Thakur, S.L. Sinsabaugh, M.J. Isaacson, M.S. Wong, S.L. Biswal, Sci. Rep., 2 (2012) 795 .

[5] A. Xing, J. Zhang, Z.H. Bao, Y.F. Mei, A.S. Gordin, K.H. Sandhage, Chem. Commun., 49 (2013) 6743-6745.

[6] H. Wu, N. Du, X.X. Shi, D.R. Yang, J. Power Sources, 331 (2016) 76-81.

[7] Y.Q. Lai, J.R. Thompson, M. Dasog, Chem.: Eu. J., 24 (2018) 7913-7920.

[8] D.H. Wang, X.B. Jin, G.Z. Chen, Annual Reports Section "C" (Physical Chemistry), 104 (2008) 189-234.

[9] W. Kroll, Trans. Electrochem. Soc., 78 (1940) 35-47.

[10] G.Z. Chen, D.J. Fray, T.W. Farthing, Nature, 407 (2000) 361-364.

[11] R.L. Centeno-Sánchez, D.J. Fray, G.Z. Chen, J. Mater. Sci., 42 (2007) 7494-7501.

[12] C. Schwandt, G.R. Doughty, D.J. Fray, Key Eng. Mater., 436 (2010) 13-25.

[13] R. Barnett, K.T. Kilby, D.J. Fray, Metall. Mater. Trans. B, 40 (2009) 150-157.

[14] D.S.M. Vishnu, N. Sanil, K. Mohandas, K. Nagarajan, Acta Metall. Sin-Engl, 30 (2017) 218-227.

[15] K. Mohandas, D. Fray, J. Appl. Electrochem., 41 (2011) 321-336.

[16] X. Ping, K. Liu, Y. Liu, L. Yuan, B. Yao, X. Zhao, Z. Chai, W. Shi, J. Electrochem. Soci., 164 (2017) 888-894.

[17] Y.-K. Zhong, K. Liu, Y.-L. Liu, Y.-X. Lu, T.-Q. Yin, L. Wang, Z.-f. Chai, W.-Q. Shi, J. Electrochem. Soc., 166 (2019) 276-282.

[18] T. Nohira, K. Yasuda, Y. Ito, Nat. Mater., 2 (2003) 397.

[19] J. Cai, X.T. Luo, C.H. Lu, G.M. Haarberg, A. Laurent, O.E. Kongstein, S.1. Wang, Trans. Nonferrous Met. Soc. China, 22 (2012) 3103-3107. 
[20] K. Yasuda, T. Nohira, K. Amezawa, Y.H. Ogata, Y. Ito, J. Electrochem. Soc., 152 (2005) D69-D74.

[21] W. Xiao, X.B. Jin, Y. Deng, D.H. Wang, X.H. Hu, G.Z. Chen, ChemPhysChem, 7 (2006) 1750-1758.

[22] X.B. Jin, P. Gao, D.H. Wang, X.H. Hu, G.Z. Chen, Angew. Chem. Int. Ed., 43 (2004) 733-736.

[23] G.Z. Chen, E. Gordo, D.J. Fray, Metall. Mater. Trans. B, 35 (2004) 223-233.

[24] J. Yang, S. Lu, S. Kan, X. Zhang, J. Du, Chem. Commun., 22 (2009) 3273-3275.

[25] J.Y. Yang, S.G. Lu, H.Y. Ding, X.J. Zhang, S.R. Kan, Chinese J. Inorg. Chem., 26 (2010) 1837-1843.

[26] Y. Nishimura, T. Nohira, K. Kobayashi, R. Hagiwara, J. Electrochem. Soc., 158 (2011) E55-E59.

[27] J. Zhao, J. Li, P.l. Ying, W.h. Zhang, L.j. Meng, C. Li, Chem. Commun., 49 (2013) 4477-4479.

[28] Y. Dong, T. Slade, M.J. Stolt, L.S. Li, S.N. Girard, L.Q. Mai, S. Jin, Angew. Chem. Int. Ed., 56 (2017) 14453-14457.

[29] S. Fang, H. Wang, J.Y. Yang, S.G. Lu, B. Yu, J.T. Wang, C.R. Zhao, Rare Metals, 38 (2019) 776-782.

[30] J. Zhao, S.M. Lu, L.Y. Hu, C. Li, J. Energy Chem., 22 (2013) 819-825.

[31] M. Tokushige, H. Tsujimura, T. Nishikiori, Y. Ito, Electrochim. Acta, 100 (2013) 300-303.

[32] E. Ergül, I. Karakaya, M. Erdoğan, J. Alloys Compd., 509 (2011) 899-903.

[33] X. Yang, K. Yasuda, T. Nohira, R. Hagiwara, T. Homma, Metall. Mater. Trans. B, 45 (2014) 1337-1344.

[34] X. Yang, K. Yasuda, T. Nohira, R. Hagiwara, T. Homma, Metall. Mater. Trans. B, 47 (2016) 788-797.

[35] J.Y. Yang, S.G. Lu, S.R. Kan, X.J. Zhang, H.Y. Ding, Chinese J. Inorg. Chem., 25 (2009) 756-760.

[36] H. Nishihara, T. Suzuki, H. Itoi, B.-G. An, S. Iwamura, R. Berenguer, T. Kyotani, Nanoscale, 6 (2014) 10574-10583.

[37] K. Yasuda, T. Nohira, K. Kobayashi, N. Kani, T. Tsuda, R. Hagiwara, Energy Technol., 1 (2013) 245-252.

[38] K. Yasuda, T. Nohira, Y. Ito, J. Phys. Chem. Solids, 66 (2005) 443-447.

[39] W. Xiao, X. Wang, H.Y. Yin, H. Zhu, X.H. Mao, D.H. Wang, RSC Adv., 2 (2012) 7588-7593.

[40] K. Yasuda, T. Nohira, R. Hagiwara, Y.H. Ogata, Electrochim. Acta, 53 (2007) 106-110.

[41] E. Ergul, I. Karakaya, M. Erdogan, MRS Online Proceedings Library Archive, 1210 (2009).

[42] J.R. Szczech, S. Jin, Energy Environ. Sci., 4 (2011) 56-72.

[43] Y. Son, S. Sim, H. Ma, M. Choi, Y. Son, N. Park, J. Cho, M. Park, Adv. Mater., 30 (2018) 1705430.

[44] T. Hatchard, J. Dahn, J. Electrochem. Soc., 151 (2004) A838-A842. 
[45] X.H. Liu, L. Zhong, S. Huang, S.X. Mao, T. Zhu, J.Y. Huang, ACS Nano, 6 (2012) 1522-1531.

[46] W. Weng, C. Zeng, W. Xiao, Acs Appl. Mater. Interfaces, 11 (2019) 9156-9163.

[47] W. Weng, W. Xiao, ACS Appl. Energy Mater., 2 (2018) 804-813.

[48] W. Xiao, J. Zhou, L. Yu, D.H. Wang, X.W. Lou, Angew. Chem. Int. Ed., 55 (2016) 7427-7431.

[49] Z. Zhou, Y. Zhang, Y. Hua, P. Dong, Y. Lin, M. Xu, D. Wang, X. Li, L. Han, J. Duan, J. Alloys Compd., 751 (2018) 307-315.

[50] Z.R. Zhou, P. Dong, D.Y. Wang, M. Liu, J.G. Duan, G.P. Nayaka, D. Wang, C.Y. Xu, Y.X. Hua, Y.J. Zhang, J. Alloys Compd., 781 (2019) 362-370.

[51] W. Xiao, X.B. Jin, G.Z. Chen, J. Mater. Chem. A, 1 (2013) 10243-10250.

[52] X.Y. Zou, H.W. Xie, Y.C. Zhai, X.C. Lang, J. Zhang, Electrolysis process for preparation of solar grade silicon, in: Advanced Materials Research, Trans Tech Publ, 2012, 697-702.

[53] S.K. Cho, F.-R.F. Fan, A.J. Bard, Electrochim. Acta, 65 (2012) 57-63.

[54] S.K. Cho, F.R.F. Fan, A.J. Bard, Angew. Chem. Int. Ed., 51 (2012) 12740-12744. [55] X.G. Liu, P.R. Coxon, M. Peters, B. Hoex, J.M. Cole, D.J. Fray, Energy Environ. Sci., 7 (2014) 3223-3263.

[56] E. Juzeliunas, A. Cox, D.J. Fray, Electrochem. Commun., 12 (2010) 1270-1274.

[57] E. Juzeliunas, A. Cox, D.J. Fray, Electrochim. Acta, 68 (2012) 123-127.

[58] P.R. Coxon, M. Coto, E. Juzeliunas, D.J. Fray, Pro. Nat. Sci.: Mater., 25 (2015) 583-590.

\section{Graphical Abstract}

The electro-reduction of $\mathrm{SiO}_{2}$ to pure silicon occurs at the metal- $\mathrm{SiO}_{2}$-electrolyte threephase interlines where solid $\mathrm{SiO}_{2}$ is electrochemically reduced to silicon, and $\mathrm{O}^{2-}$ dissolves in the electrolyte, transfers to the anode.

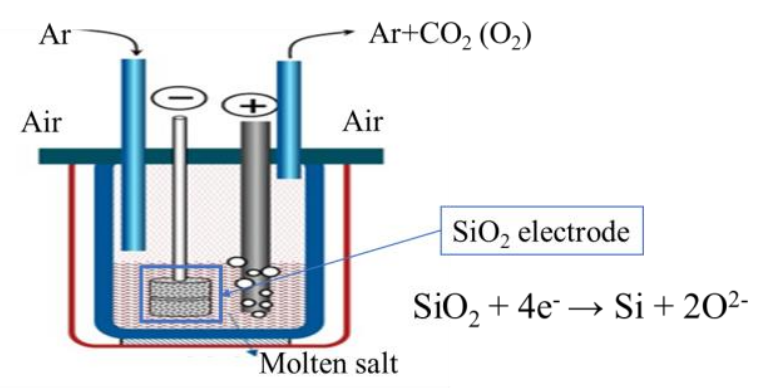

